NBER WORKING PAPER SERIES

\title{
WHAT CAN STOCKOUTS TELL US ABOUT INFLATION? EVIDENCE FROM ONLINE MICRO DATA
}

\author{
Alberto Cavallo \\ Oleksiy Kryvtsov \\ Working Paper 29209 \\ http://www.nber.org/papers/w29209 \\ NATIONAL BUREAU OF ECONOMIC RESEARCH \\ 1050 Massachusetts Avenue \\ Cambridge, MA 02138 \\ September 2021, Revised February 2022
}

We are grateful to Jenny Duan and Joaquin Campabadal for excellent research assistance, and to Caroline Coughlin and Manuel Bertolotto for providing access and help with the micro data. We thank George Alessandria, Greg Kaplan, Jim MacGee, Emi Nakamura, and seminar participants at the Bank of Canada, Bank of Finland, CEBRA, Council of Economic Advisers, HBS-PROM, and the 2021 Canadian Economic Association meetings for helpful comments and suggestions. Alberto Cavallo is a shareholder of PriceStats LLC, the private company that provided proprietary data used in this paper without any requirements to review the findings. The views expressed here are ours, and they do not necessarily reflect the views of the Bank of Canada or the National Bureau of Economic Research.

NBER working papers are circulated for discussion and comment purposes. They have not been peer-reviewed or been subject to the review by the NBER Board of Directors that accompanies official NBER publications.

(C) 2021 by Alberto Cavallo and Oleksiy Kryvtsov. All rights reserved. Short sections of text, not to exceed two paragraphs, may be quoted without explicit permission provided that full credit, including (O) notice, is given to the source. 
What Can Stockouts Tell Us About Inflation? Evidence from Online Micro Data

Alberto Cavallo and Oleksiy Kryvtsov

NBER Working Paper No. 29209

September 2021, Revised February 2022

JEL No. D22,E31,E37

\begin{abstract}
$\underline{\text { ABSTRACT }}$
We use a detailed micro dataset on product availability to construct a direct high-frequency measure of consumer product shortages during the 2020-2021 pandemic. We document a widespread multi-fold rise in shortages in nearly all sectors early in the pandemic. Over time, the composition of shortages evolved from many temporary stockouts to mostly discontinued products, concentrated in fewer sectors. We show that unexpected product shortages have significant inflationary effects within three months. We develop a model of inventories in a sector facing both demand and cost disturbances, and use the observed joint dynamics of stockouts and prices to show that these effects can be associated with elevated cost of replenishing inventories.
\end{abstract}

\author{
Alberto Cavallo \\ Harvard Business School \\ Morgan Hall 287 \\ Soldiers Field \\ Boston, MA 02163 \\ and NBER \\ acavallo@hbs.edu \\ Oleksiy Kryvtsov \\ Bank of Canada \\ Economic and Financial Research Department \\ 234 Wellington Street \\ Ottawa, Ontario K1A 0G9 \\ Canada \\ oleksiy.kryvtsov@gmail.com
}


"As the reopening continues, shifts in demand can be large and rapid, and bottlenecks, hiring difficulties, and other constraints could continue to limit how quickly supply can adjust, raising the possibility that inflation could turn out to be higher and more persistent than we expect."

- Jerome Powell (June 2021) $)^{1}$

\section{Introduction}

One of the most striking economic implications of the global COVID-19 pandemic is the severe disruption of the supply of goods to final consumers in a context of quickly rising demand. Globally, these forces caused bottlenecks in shipping networks and disrupted the flow of goods along international supply chains. Domestically, the pandemic increased the cost of business operations, undercutting retailers' efforts to manage inventories amid volatile swings in consumer demand. $^{2}$ As a result, retailers and consumers faced shortages in a wide range of goods, from toilet paper to electronics. By early 2021, the persistence of shortages raised concerns about their inflationary impact, particularly in the United States, where prices were rising at rates not seen in more than a decade. ${ }^{3}$ Although there is evidence of these disruptions for some products in manufacturing, there is no systematic evidence on shortages of consumer products. ${ }^{4}$ Furthermore, the degree of inflationary pressures associated with such shortages has been widely debated and remains unknown.

In this paper, we provide a direct high-frequency measure of consumer product shortages during the pandemic. The measure captures product unavailability in the micro data collected by PriceStats from the websites of 70 large retailers in 7 countries - the United States, Canada, China, France, Germany, Japan, and Spain-from November 1, 2019, to May 1, 2021. The dataset spans a wide range of consumer goods, including Food and Beverages, Household, Health, Electronics, and Personal Care products, covering between $62 \%$ and $80 \%$ of the goods consump-

\footnotetext{
${ }^{1}$ Transcript of Fed Chair Powell's Statement on June 16, 2021, available at https://www. federalreserve.gov/ mediacenter/files/FOMCpresconf20210616.pdf

${ }^{2}$ See Hassan, Hollander, Van Lent, Schwedeler, and Tahoun (2020) and Meier and Pinto (2020) for some early results of the COVID-19 impact on the U.S. firms and sectors.

${ }^{3}$ In Appendix Figure A4 we show that the U.S. annual inflation rate in March and April 2021 has been at the highest level recorded for those calendar months in the past 10 years. See Foster, Meyer, and Prescott (2021) for survey results that connect firm-level concerns about supply disruptions to rising expectations of inflation.

${ }^{4}$ See Krolikowski and Naggert (2021) for an analysis of shortages in car manufacturing. Mahajan and Tomar (2021) provide evidence of food supply chain disruptions in India.
} 
tion weight. The dataset also contains product-level prices, allowing us to exploit the dataset's rich time and cross-section details to assess inflationary effects of shortages.

The paper consists of three parts. We first document the dynamics of unavailable products ("temporary stockouts") and discontinued products ("permanent stockouts") across sectors and countries over the course of the pandemic. We then establish the degree to which stockouts co-move with sector prices. Finally, we provide a formal analysis of the link between stockouts, prices, and costs using a model of a sector of monopolistic firms with inventories.

There are three distinct patterns of stockout behavior that are common across most sectors and countries during this period. First, there was a widespread rise in shortages early in the pandemic affecting nearly all categories of consumer goods. In particular, in the United States, total stockouts rose from a pre-pandemic level of around 14\% in 2019 to over 35\% in early May 2020. The stockouts rose first for health and personal care goods, but quickly spread to other categories, with increases ranging from 19 percentage points (ppt) for "Furnishings and Household" goods to above 50 ppt for "Food and Beverages." All stockouts recovered partially during the summer, but rose again and remained close to 30\% in May 2021.

Second, the composition of shortages changed significantly over time. Temporary stockouts, which are more visible to consumers because they are flagged by retailers, rose sharply in most sectors and countries early on and then recovered gradually over time. By the end of 2020, they had fallen even below pre-pandemic levels for most countries in our sample. By contrast, permanent stockouts, which had also increased quickly, remained elevated or continued growing in most countries after July 2020. In particular, in the United States, the share of discontinued products remained close to its peak of around $20 \%$ by May 2021 .

Third, over time stockouts became increasingly concentrated in fewer categories. For example, in the United States, stockouts remained persistently high for "Food and Beverages" and "Electronics," but in other major categories of goods they returned roughly to pre-pandemic levels.

Next, we show that these product shortages were associated with rising prices in most countries. The magnitude of the inflationary effect of shortages is statistically and economically significant. For example, in the United States, a unexpected doubling of the weekly stockout rate from $10 \%$ to $20 \%$ brings about a 0.10 ppt increase in the monthly inflation rate in a 3 -digit 
sector. It takes about a month for inflation to respond, with an increase that peaks at seven weeks and lasts for approximately three months.

In the final part of the paper, we explicitly account for the endogeneity of stockouts by incorporating the cost of replenishing inventory stocks. Building on Kryvtsov and Midrigan (2013), we develop a model of joint dynamics of stockouts and prices in a sector facing exogenous demand and cost disturbances. We use the model to derive an empirical specification for estimating the cost behind the observed dynamics of stockouts and prices at a sector level. We then construct empirical responses of sector stockouts and inflation to estimated cost shocks. ${ }^{5}$

Our estimation results imply a statistically and economically significant link between costs, stockouts, and inflation. The estimated cost dynamics resemble those from observed stockout behaviors, validating the idea of using stockouts for gauging the emergent cost pressures. The cost underlying temporary stockouts dominated early in the pandemic, while the cost driving permanent stockouts increased gradually, stressing the need to measure different types of product unavailability for an accurate assessment of cost pressures. Furthermore, accounting for the endogeneity of stockouts makes the estimated inflationary effects stronger immediately after the cost shock, but also less persistent.

\section{Data and Stockout Measurement}

We use data obtained from the websites of large retailers that sell products both online and in brick-and-mortar stores. The data were collected by PriceStats, a private firm related to the Billion Prices Project (Cavallo, 2013, and Cavallo and Rigobon, 2016). ${ }^{6}$ Table 1 summarizes some key dimensions of our dataset. We use information from 70 retailers in 7 countries: Canada, China, France, Germany, Japan, Spain, and the United States. The sample ends on May 1, 2021, and starts on January 1, 2019, for the United States and on November 1, 2019, for all other countries. For each product we have an id, the price, and out-of-stock indicator, which can change on a daily basis. In addition, each product is classified in a 3-digit COICOP classification, covering five major categories of goods: "Food and Non-Alcoholic Beverages", "Furnishings and Household", "Health", "Recreation and Culture" (mostly electronics), and "Other Goods"

\footnotetext{
${ }^{5}$ Bils and Kahn (2000), Kryvtsov and Midrigan (2010, 2013), Bils (2016) analyze the observed behavior of inventories and stockouts to infer the underlying dynamics of costs and markups over the business cycle. Aguirregabiria (1999) shows that inventories and fixed ordering costs are important for the dynamics of retail prices.

${ }^{6}$ See Cavallo (2017) for a comparison of online and brick-and-mortar prices.
} 
(including personal care products). ${ }^{7}$ The data cover between $62 \%$ and $80 \%$ of the Consumer Price Index (CPI) weight of all goods, depending on the country.

\begin{tabular}{lcccc}
\hline \hline & Products & Retailers & $\begin{array}{c}\text { Coverage of All } \\
\text { CPI Weights, (\%) }\end{array}$ & $\begin{array}{c}\text { Coverage of Goods } \\
\text { CPI Weights, (\%) }\end{array}$ \\
\hline Canada & 194,151 & 11 & 27 & 80 \\
China & 49,685 & 3 & 38 & 76 \\
France & 372,962 & 11 & 32 & 63 \\
Germany & 297,320 & 13 & 27 & 52 \\
Japan & 95,313 & 7 & 30 & 68 \\
Spain & 171,400 & 8 & 31 & 56 \\
USA & 777,554 & 17 & 21 & 62 \\
\hline All & $1,958,385$ & 70 & 29 & 65 \\
\hline \hline
\end{tabular}

\section{Table 1: Data Coverage}

Notes: All retailers are large "multi-channel" firms selling both online and in brick-and-mortar stores. To be included in our sample, they must also display an out-of-stock indicator for each product on their websites. Coverage for CPI weights is calculated by adding the official CPI weights of all 3-digit COICOP categories included in the data for each country. Coverage percentages for "All" are unweighted arithmetic means across all countries.

Using these micro data, we measure two distinct types of stockouts. First, we focus on products labeled by the retailers as being out of stock, as illustrated in Figure 1.

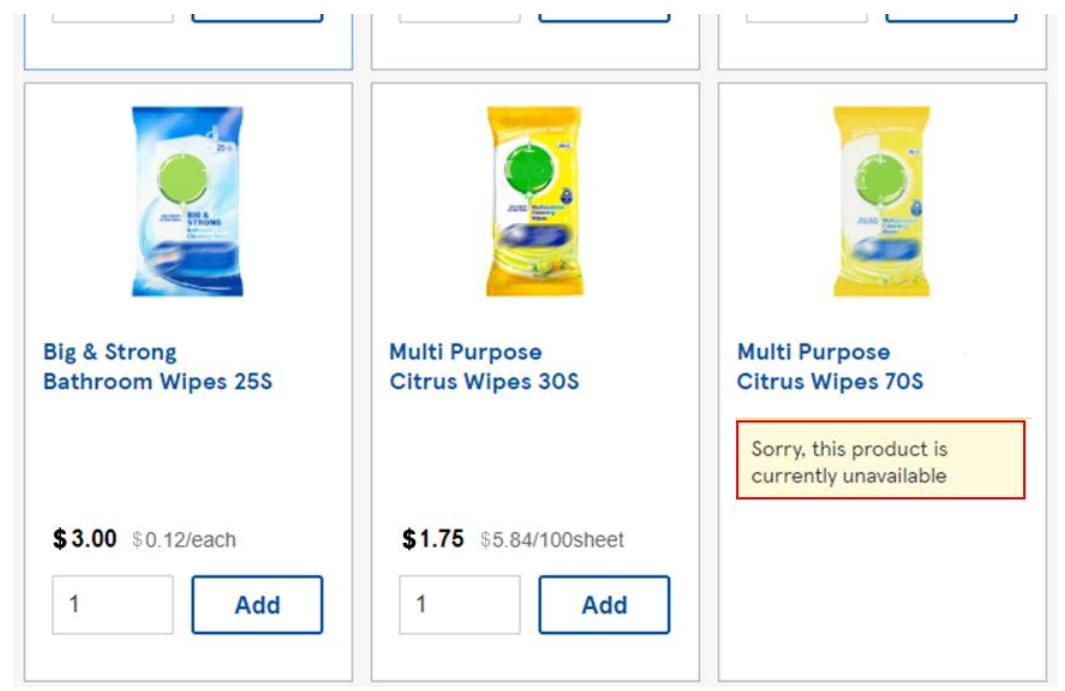

Figure 1: Identifying Stockouts on a Retailer's Website

Notes: This figure provides an illustration of how we identify products that are out of stock. All retailers in our sample display messages like the one in this example, which allows us to create an indicator variable in the dataset for goods that are out-of-stock on a given day ("Temporary Stockouts"). We also identify products that disappear (or appear) from the website and calculate the net number of discontinued goods relative to pre-pandemic levels ("Permanent Stockouts").

\footnotetext{
${ }^{7}$ See UN (2018) for details on the COICOP classification structure.
} 
Retailers typically indicate stockouts on their websites via text or images displayed on or around the product's listing. Such occurrences are recorded in the database as an out-of-stock indicator. The fact that retailers display out-of-stock information implies that they expect these products to eventually be back in stock, which is why we label them as "temporary stockouts." They are similar to a product missing on its shelf in a brick-and-mortar store. To obtain a highfrequency time series, we calculate the share of "Temporary Stockouts" (TOOS) in a 3-digit COICOP sector $j$ in country $c$ on day $t$ as a percentage of all products available for purchase on that day:

$$
\operatorname{TOOS}_{t, j, c}=\frac{\text { out-of-stock }}{t, j, c} .
$$

The second type of stockouts accounts for the fact that retailers discontinued many products and removed them from their websites. Although some discontinued goods were replaced with new varieties, the total number of products available to consumers declined significantly in most countries. We therefore compute a complementary stockout measure, "Permanent Stockouts" (POOS), as the percentage decline in the number of available products in a sector relative to their average level in January 2020:

$$
\operatorname{POOS}_{t, j, c}=1-\frac{\text { total products }_{t, j, c}}{\text { total products }_{J a n 2020, j, c}} .
$$

Finally, we define a broad measure of stockouts, all stockouts $\left(A O O S_{t, j, c}\right)$, as the sum of temporary and permanent stockouts. To obtain aggregate indices consistent with the official CPI in each country, we aggregate values of the corresponding 3-digit series using a geometric average with official CPI category weights $w_{j, c}$ obtained from the national statistical office in each country:

$$
O O S_{t, c}=\prod_{j} O O S_{t, j, c}^{w_{j, c}},
$$

where $O O S=\{T O O S, P O O S, A O O S\}$

\section{Stockouts and Inflation}

In this section we describe stockout dynamics and study their impact on sectoral inflation. We first focus our analysis on the United States, where the data cover more sectors and the time series are longer, and later discuss some similarities and differences with other countries. 


\subsection{Stockout Dynamics}

Stockouts experienced substantial variation over the course of the crisis. In particular, three main patterns stand out. First, there was a large increase in temporary and permanent stockouts in the wake of the pandemic, affecting most countries and sectors. Second, after a year and a half, temporary stockouts returned to normal levels. By contrast, permanent stockouts still remain persistently high in some countries and sectors. Third, stockouts are increasingly concentrated in fewer sectors, suggesting a gradual return to normalcy is under way.

\subsubsection{U.S. Stockouts}

We first highlight these patterns using U.S. data (Figures 2 and 3). The plot in Figure 2(a) shows stockouts $\left(A O O S_{t, U S}\right)$ rising quickly in the first quarter of the crisis, from a pre-pandemic level of around 14\% in 2019 to over 35\% in early May 2020. They recovered partially in the summer of 2020, but rose to reach nearly peak levels again by May 2021. This pattern is consistent with the percentage of firms reporting some kind of supply disruption in the "Small Business Pulse Survey" conducted by the U.S. Census Bureau between May 2020 and April 2021 (see Figure A1 in the Appendix). ${ }^{8}$

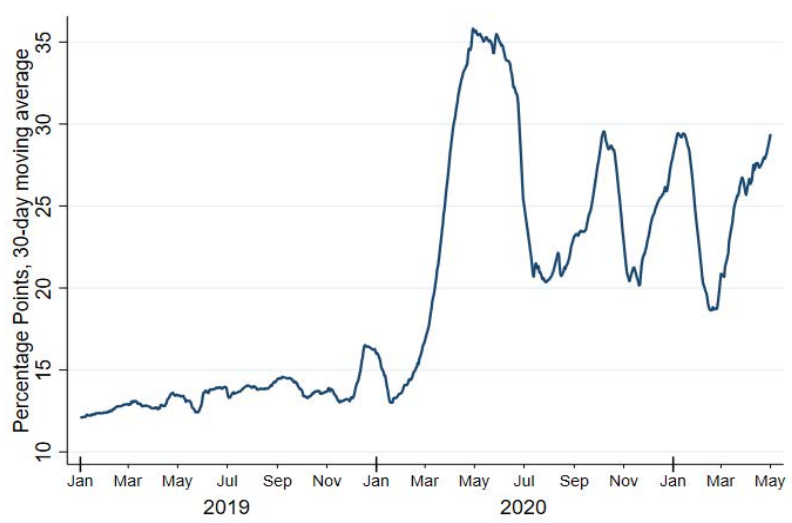

(a) All Stockouts

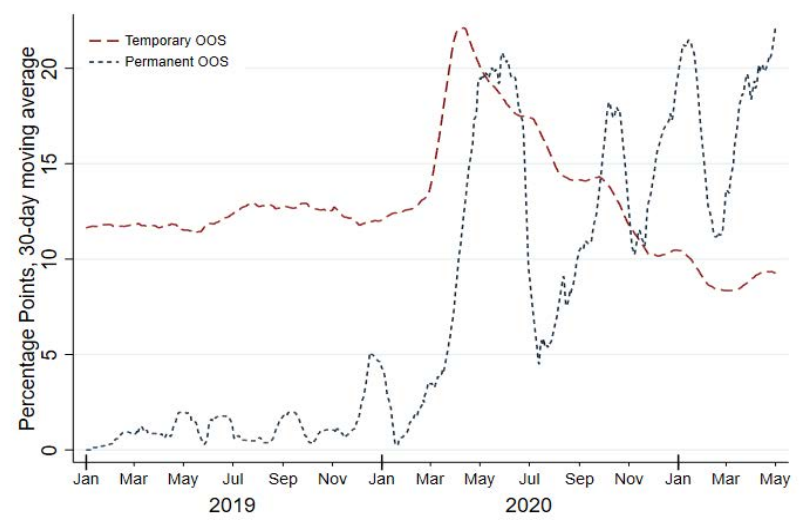

(b) Temporary and Permanent Stockouts

Figure 2: Stockouts in the United States, 2019-2021

Notes: In panel (a) we plot all stockouts $A O O S_{t, c}$. In panel (b) we plot separately temporary $T O O S_{t, c}$, measured using the retailer out-of-stock indicators, and permanent stockouts $P O O S_{t, c}$, measured as the fall in the total number of available products relative to pre-pandemic levels.

The composition of stockouts changed significantly over time, as shown in Figure 2(b). Tem-

\footnotetext{
${ }^{8}$ U.S. Census Bureau (2021).
} 
porary stockouts, which are more visible to consumers, rose quickly from $12 \%$ to $22 \%$ in March 2020, and then recovered gradually over time. By November, they were back to pre-pandemic levels, and continued to fall further in subsequent months. Permanent stockouts also increased sharply at the beginning of the pandemic, but unlike temporary stockouts, they continued growing, as shown in Figure 2(b). Initially, about $20 \%$ of products had been discontinued by the end of April 2020. After recovering in July, permanent stockouts started to increase again, and by May 2021 they were once again peaking around 20\% over pre-pandemic levels.

Elevated stockouts affected all sectors but were more persistent in "Food and Beverages" and "Electronics." This can be seen in Figure 3, where we plot stockout levels for five major good categories in the United States. To facilitate the comparisons, we normalize the series by subtracting the average level during January 2020 for each sector.

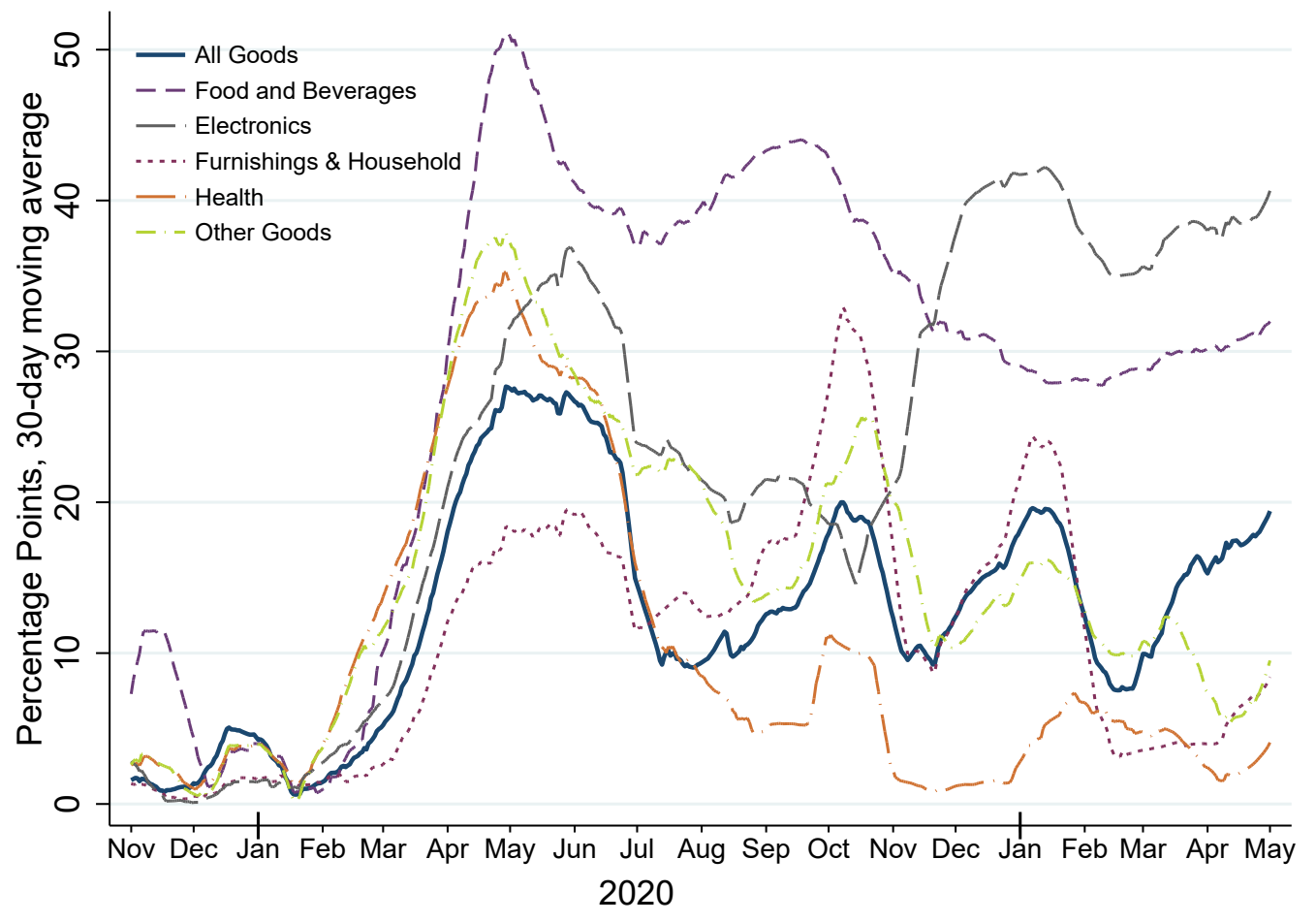

Figure 3: All Stockouts in U.S. Sectors

Notes: The initial level of $A O O S$ varies greatly by sector, so in order to facilitate the comparison, here we plot the change relative to pre-pandemic levels, given by $A O O S_{t, c}-A O O S_{J a n 2020, c}$.

As expected in a health crisis, stockouts rose first for health and personal care goods. Thereafter, stockouts quickly spread to other categories. In May 2020, the stockout increase ranged from 19 ppt for "Furnishings and Household" goods to above 50 ppt for "Food and Beverages." 
Some categories recovered gradually over time, and by May 2021 stockouts were finally back to normal in "Health," "Furnishings and Household," and "Other Goods." However, the disruptions were more persistent for "Food and Beverages," where stockouts remained above 30 ppt above pre-pandemic levels, and "Electronics," where they surged in recent months. These findings are consistent with U.S. media reports on these two sectors, where supply problems in electronics are linked to a global computer-chip shortage, and those in food to labor and raw material shortages. ${ }^{9}$

\subsubsection{Other Countries}

Stockout patterns identified in the U.S. data are broadly similar to those in other countries, but there are also important differences. Figure 4 shows both temporary and permanent stockouts for all seven countries. To facilitate the comparisons of temporary stockouts, in Figure 4(a) we plot the incremental change relative to the pre-pandemic levels, given by $T O O S_{t, c}-T O O S_{J a n 2020, c}$.

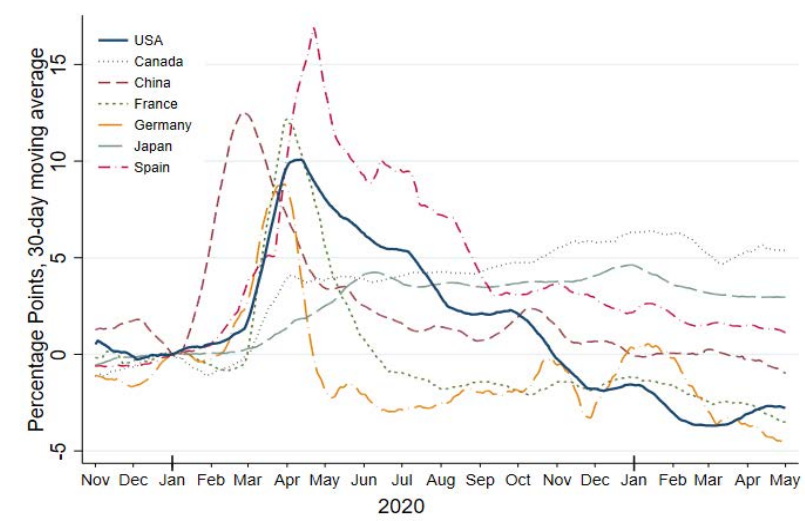

(a) Temporary Stockouts

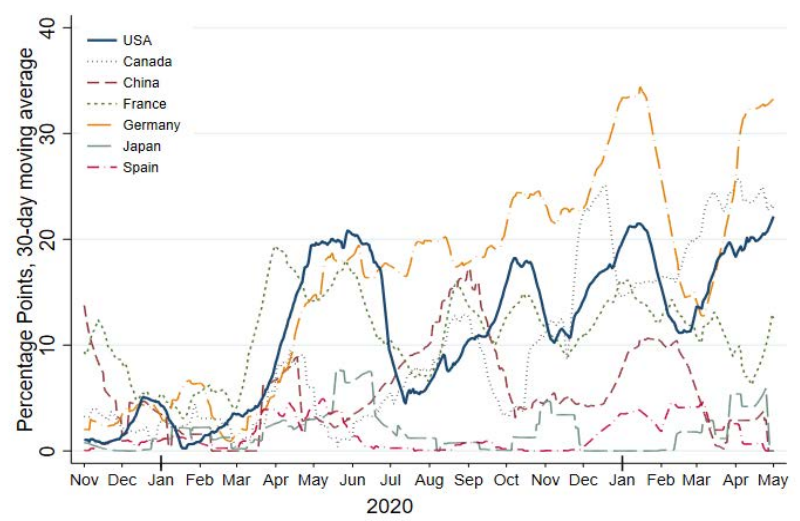

(b) Permanent Stockouts

Figure 4: Temporary and Permanent Stockouts in 7 Countries

Notes: In panel (a) we plot $T O O S_{t, c}-T O O S_{J a n 2020, c}$, the change in temporary stockouts relative to pre-pandemic levels. In panel (b) we plot permanent stockouts $P O O S_{t, c}$ measured as the fall in the total number of available products relative to pre-pandemic levels.

In most countries, temporary stockouts followed a common pattern, rising sharply during the first two months of the pandemic and then gradually returning to pre-COVID levels over time. Yet, there are noteworthy differences in the timing and magnitudes of the changes. Temporary stockouts peaked first in China, where the pandemic started. Stockouts there rose by $12 \mathrm{ppt}$

\footnotetext{
${ }^{9}$ See Fitch (2021) and Kang (2021).
} 
from their pre-pandemic levels during the month of February 2020 and then gradually declined back to normal around July 2020. European countries were next, peaking in April 2020 with an increase between 10 and 15 ppt. For Germany and France, the recovery back to normal levels was relatively quick, but in Spain temporary stockouts took longer to fall, normalizing only by the end of 2020. The two outliers here are Canada and Japan, where temporary stockouts rose only gradually, by around 5 ppt, and remained elevated.

The behavior of permanent stockouts differs a lot more across countries, as shown in Figure 4(b). At one end, countries such as China and Japan had no significant increase in permanent stockouts during the pandemic. This means that retailers in those countries managed to continue offering roughly the same number of products for sale. By contrast, all other countries experienced substantial losses in product varieties. The increase in permanent stockouts was particularly large in Canada and Germany. All in all, heterogeneity in stockout patterns, which we also document at a sector level, can be used to identify the effects of product unavailability on inflation rates across countries and sectors.

\subsection{Impact on Inflation}

Having documented the dynamic behavior of stockouts during the pandemic, we now turn to their impact on prices. For most of 2020, inflation was relatively low, but by the end of the year consumer prices started rising sharply in most countries, as seen in Figure 5. The graph on the left shows that, relative to pre-pandemic levels in January 2020, the rise in the official CPI levels was more pronounced in the United States, Canada, and Germany, the same countries where stockouts appeared to be more persistent. Similar inflation dynamics can be seen in online prices, as shown on the graph on the right.

The sudden rise of inflation led to much speculation about its causes, particularly in the United States, where cost pressures and supply disruptions were often cited by policy-makers as a potential source of transitory price pressures (Bernstein and Tedeschi, 2021; Helper and Soltas, 2021). We therefore start our analysis with the United States. 


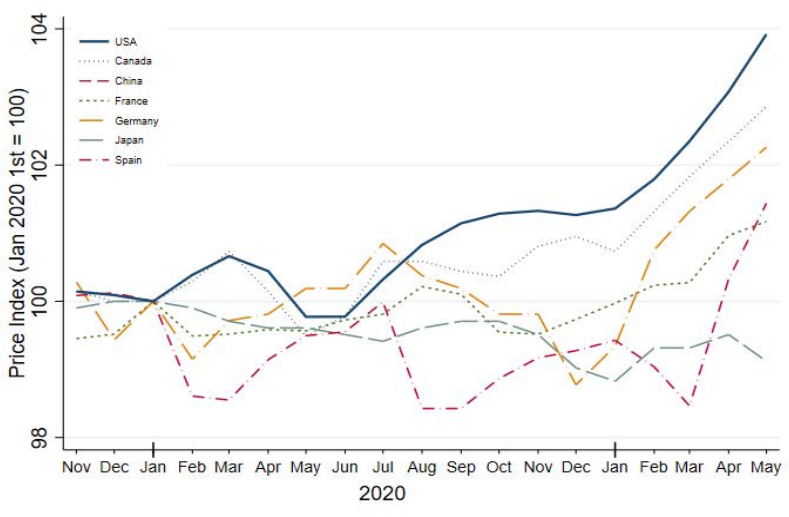

(a) Official CPIs

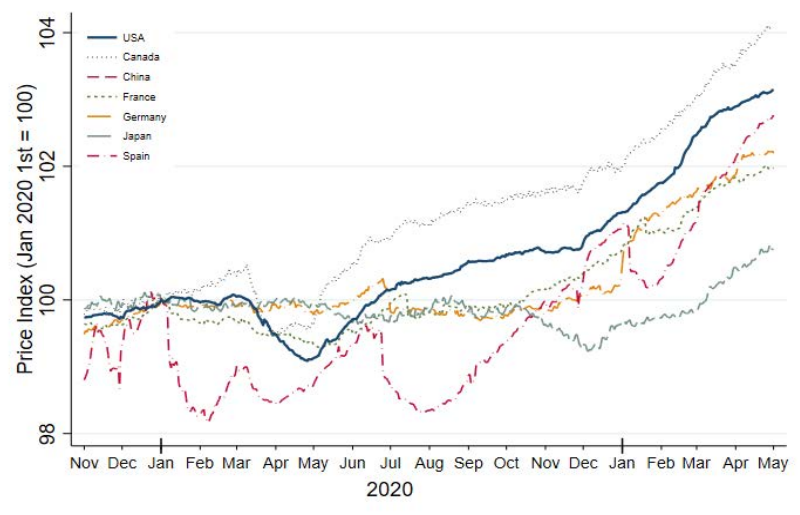

(b) Online Price Indices

Figure 5: CPI and Online Price Indices

Notes: Figure (a) shows the official all-items CPI in each country. Figure (b) shows equivalent price indices constructed by PriceStats using the same online data source used in this paper.

\subsubsection{U.S. Inflation}

For some categories, the connection between stockouts and prices is apparent in simple graphs, such as the one in Figure 6(a), where we plot a sequential scatter plot with the level of monthly inflation and temporary stockouts for "Food and Beverages" in the United States. The graph shows that stockouts increased sharply in March 2020, and prices rose in April 2020, and then both fell in subsequent months. For most categories, however, the connection between stockouts and prices is not so clear. For example, in Figure 6(b) we find only a weak positive relationship between stockouts and monthly inflation rates at the 2-digit category level in the United States.

The effects of shortages on inflation are likely to take several weeks or months, as retailers face constraints on how quickly they can raise prices in an environment that resembles the aftermath of a natural disaster (Cavallo, Cavallo, and Rigobon, 2014). Some evidence of these delayed effects on inflation can be seen in Table 2, where we report the coefficients for simple regressions of the U.S. inflation rates on the level of stockouts at 3-digit COICOP level with category fixed effects. 


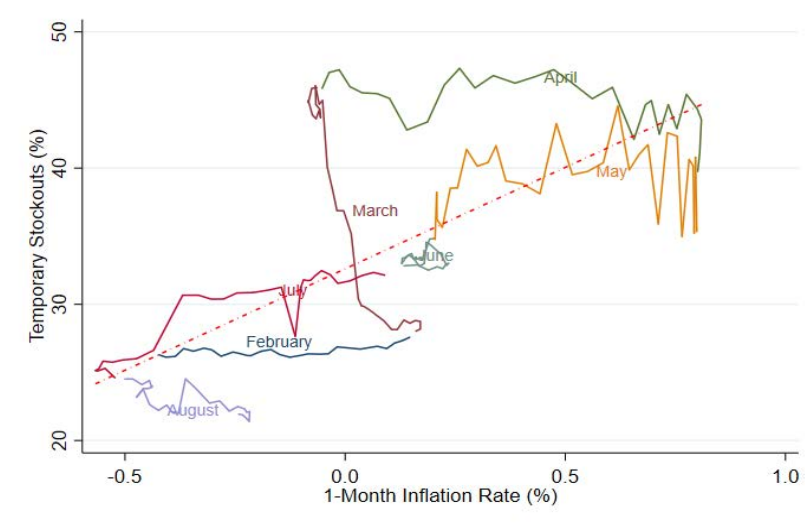

(a) Food and Beverages

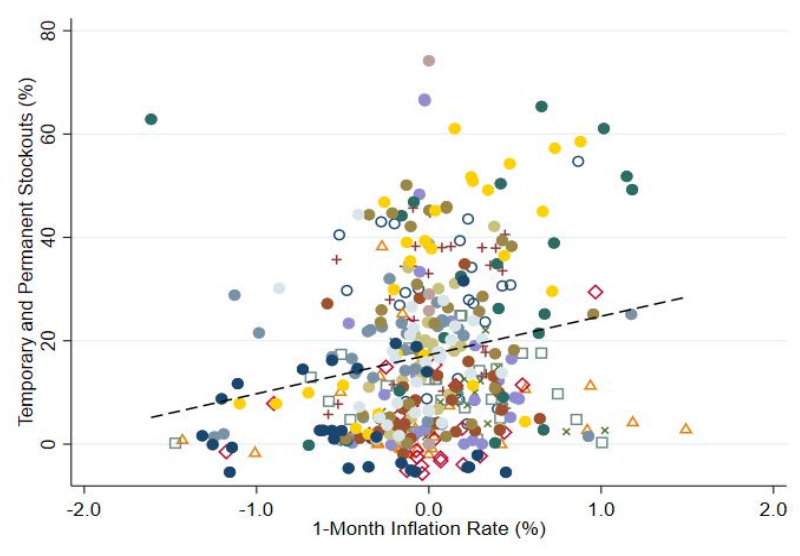

(b) 2-digit Sectors

Figure 6: U.S. Inflation and Stockouts

Notes: Figure (a) plots the daily level of temporary stockouts (y-axis) and the 1-month inflation rate (x-axis) for the "Food and Beverages" category in the United States from February to August 2020. Each color labels a different month. Figure (b) shows a scatter plot of the levels of total stockouts and 1-month inflation at 2-digit sector level in the United States, using monthly data and removing some outliers. Each color labels a different 2-digit sector. The dashed line shows the linear prediction between the two variables.

\begin{tabular}{|c|c|c|c|c|c|c|}
\hline & All Goods & Food \& Bev. & Household & Health & Electronics & Other Goods \\
\hline \multicolumn{7}{|c|}{ Monthly inflation } \\
\hline OOS $(\%)$ & $\begin{array}{c}0.001 \\
(0.000)\end{array}$ & $\begin{array}{c}0.006 \\
(0.000)\end{array}$ & $\begin{array}{c}-0.005 \\
(0.001)\end{array}$ & $\begin{array}{c}-0.006 \\
(0.001)\end{array}$ & $\begin{array}{c}-0.004 \\
(0.000)\end{array}$ & $\begin{array}{c}-0.001 \\
(0.001)\end{array}$ \\
\hline Obs. & 16,892 & 5,357 & 3,896 & 974 & 5,204 & 1,461 \\
\hline \multicolumn{7}{|c|}{ Annual inflation } \\
\hline OOS $(\%)$ & $\begin{array}{c}0.029 \\
(0.001)\end{array}$ & $\begin{array}{c}0.004 \\
(0.001)\end{array}$ & $\begin{array}{c}0.015 \\
(0.001)\end{array}$ & $\begin{array}{c}-0.039 \\
(0.004)\end{array}$ & $\begin{array}{c}0.023 \\
(0.001)\end{array}$ & $\begin{array}{c}-0.091 \\
(0.003)\end{array}$ \\
\hline Obs. & 16,856 & 5,346 & 3,888 & 972 & 5,192 & 1,458 \\
\hline
\end{tabular}

Table 2: Impact of Stockouts on Contemporaneous Inflation Rates in the United States

Notes: The table provides estimated coefficients for a regression at the 3-digit category level in the United States. The dependent variable is either the monthly (top panel) or annual (bottom panel) inflation rate, in \%. The independent variable is the level of stockouts (both temporary and permanent), in \%. All regressions are run using daily data and include 3-digit category dummies. Robust standard errors are shown in parentheses.

To gauge the relationships at short- and medium-term horizons, we use monthly and annual inflation rates, defined as the percent change in the price index over the preceding month or year. When we use monthly inflation rates, only "Food and Beverages" has a positive coefficient of 0.008 (top panel), implying that the $40 \mathrm{ppt}$ increase in stockouts (as seen in Figure 3) is associated 
with a $0.32 \%$ increase in monthly inflation. However, in all other sectors the coefficients are negative, suggesting that stockouts and inflation move in opposite directions in the short-run.

More positive correlations only appear when we use annual inflation rates, in the bottom panel. In particular, stockouts and annual inflation rates are positively related for "Food and Beverages," "Electronics," and "Household Goods." Perhaps not surprisingly, these sectors are also the ones where the increase in stockouts was the largest and most persistent. In particular, the coefficient for "Electronics" suggests that the additional 40 ppt in stockouts can account for an extra $0.92 \mathrm{ppt}$ increase in the annual inflation rate in that sector. In the Appendix we show that this could potentially account for about half of the additional annual inflation in that sector since the beginning of the pandemic.

These differences in contemporaneous correlations that use monthly and annual inflation rates suggest that the connection between stockouts and inflation is dynamic and accumulates over time. To study this further, we estimate the simultaneous responses of stockouts and inflation to a stockout disturbance at the 3-digit sector level. For now, we treat such stockout disturbance as exogenous, and we relax this assumption in the next section.

To account for the persistence in stockouts, we first estimate innovations to observed variations of sector stockouts over time using an $\mathrm{AR}(1)$ process estimated for sector $j$ 's weekly stockout rate: $O O S_{j t}=c_{j}+\beta_{j} O O S_{j t-1}+\epsilon_{j t}$. The residual term $\epsilon_{j, t}$ is the measure of the stockout shock. We then estimate the simultaneous response of sector inflation and stockouts to those innovations using the linear projections method by Jordà (2005). Let $X_{j, t}$ denote sector $j$ 's inflation (in \%, monthly rate) or stockout rate (in \%) in week $t$. We estimate the following empirical specification for the change in $X_{j, t}$ over $h$ weeks:

$$
X_{j, t+h}-X_{j, t-1}=c^{(h)}+\sum_{l=0}^{L} \beta_{l}^{(h)} \epsilon_{t-l}+\sum_{n=1}^{N} \delta_{n}^{(h)} X_{j, t-n}+D_{j}+\operatorname{error}_{j, t}^{(h)}
$$

Specification (4) conditions on the history of shocks $\epsilon_{t-l}$, where $l=0, \ldots, L$, lags of endogenous variable $X_{j, t-n}, n=1, \ldots, N$, and sector fixed effects $D_{j}$. In both estimations, we use $L=N=4$. We estimate (4) independently for each variable $X_{j, t}$ by weighted OLS regression. We conduct estimation for both stockout shocks: to temporary stockouts only and to all stockouts. Since these shocks can be persistent, we use Driscoll and Kraay (1998) standard errors for estimated coefficients. Estimated coefficients $\beta_{0}^{(h)}$ provide responses of $X_{j, t}$ to a stockout impulse at horizon 
$h=0,1, \ldots$

Figure 7 shows that stockout shocks are associated with significant and persistent responses of sector inflation in the United States. For about a month after the shock, the inflation response is near zero, consistent with our previous findings with contemporaneous monthly inflation rates. Inflation then rises, reaching its peak at $0.07 \mathrm{ppt}$ (monthly rate) by week 7 after the temporary stockout impulse, and at 0.05 ppt by week 6 after the all stockout impulse. Inflationary effect persists for about three months, gradually returning to its pre-shock level.
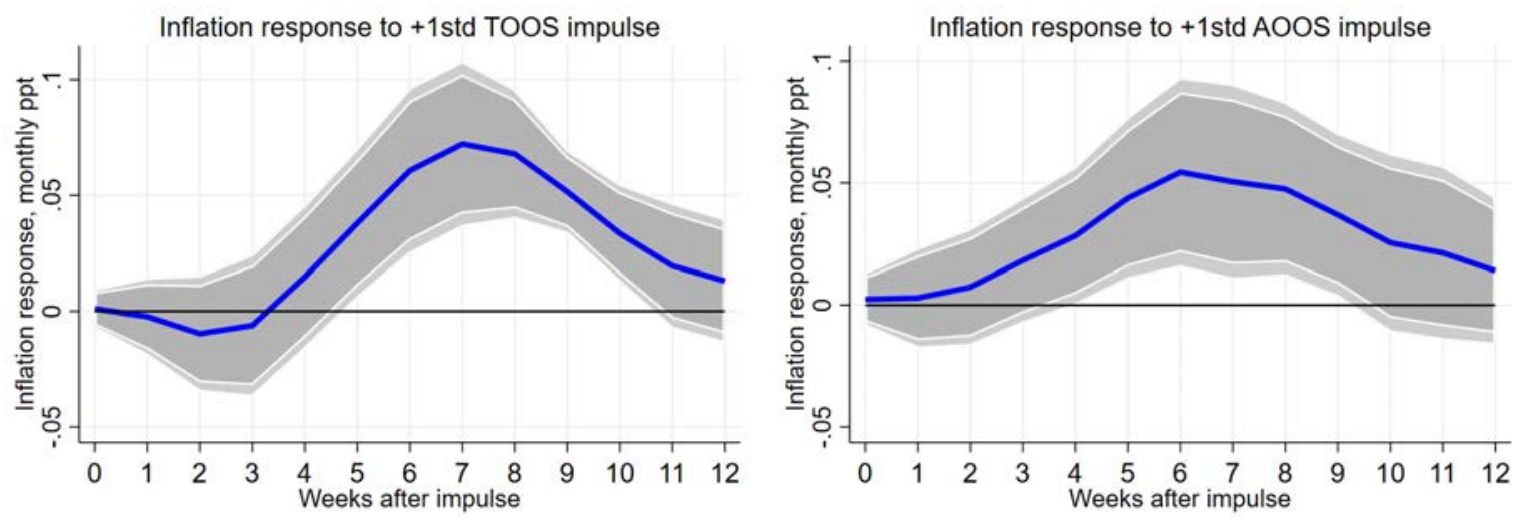

Figure 7: Inflation Response to a Stockout Shock in a 3-digit U.S. sector

Notes: The figure provides inflation responses (in ppt, monthly rate) to a +1 standard deviation stockout impulse (in ppt, average weekly rate) estimated using specification (4) for 3-digit sectors in the United States. Estimation uses two out-of-stock measures: temporary stockouts (TOOS) and all stockouts (AOOS). Shocks: temporary stockouts (left plot) and all stockouts (right plot). Shaded areas outline $90 \%$ and $95 \%$ bands based on Driscoll-Kraay standard errors.

These plots highlight the strong dynamic link between rising stockouts and inflation in the United States. Although it takes 1 to 2 months for inflation to respond to a stockout disturbance, the response is large and protracted. For example, the estimates suggest that a doubling of the weekly AOOS stockout rate from $10 \%$ to $20 \%$ - a common dynamic in the beginning of the pandemic or an emerging dynamic in 2021 - would bring about a 0.10 ppt increase in the monthly inflation rate within two months.

\subsubsection{Other Countries}

In Table 3 we extend the results to other countries. First, for each country we regress the annual inflation rate on the level of stockouts using 3-digit categories and category fixed effects. Once again, the coefficients are positive, and they are larger in countries where the stockouts have been more persistent, such as the United States and Canada. 


\begin{tabular}{lccccccc}
\hline \hline & USA & Canada & China & Germany & Spain & France & Japan \\
\hline \multirow{2}{*}{ Annual inflation } & & & & & & & \\
OOS (\%) & 0.029 & 0.027 & 0.011 & 0.011 & -0.006 & -0.011 & -0.039 \\
& $(0.001)$ & $(0.003)$ & $(0.002)$ & $(0.002)$ & $(0.001)$ & $(0.003)$ & $(0.003)$ \\
Obs. & 16,856 & 17,120 & 14,094 & 15,552 & 16,302 & 17,010 & 16,454 \\
\hline \hline
\end{tabular}

Table 3: Impact of Stockouts on Annual Inflation Rates by Country

Notes: The table provides estimated coefficients for a regression at the 3-digit category level in the United States. The dependent variable is the annual inflation rate. The independent variable is the level of stockouts (both temporary and permanent). All regressions are run using daily data and include 3-digit category dummies and period fixed effects. Robust standard errors are shown in parentheses.

Furthermore, when we re-estimate the dynamic responses across all countries, we get qualitatively similar results to those we reported in Figure 7 for the United States. Country results are provided in the Appendix. Although the responses of inflation are somewhat weaker than in the United States, the dynamics are similar, with a gradual increase that peaks after about 6 weeks.

\section{Analysis of Costs, Prices, and Stockouts}

So far, we have treated stockouts as exogenous. This is a strong assumption, of course, because firms decide their inventory levels (and therefore stockout rates) jointly with their prices, and taking into account their market conditions. This means that stockouts are endogenous, and, like prices, depend on the cost of supplying products to consumers and other sector factors. To incorporate such a mechanism in the analysis, we develop a model of a joint behavior of stockouts and prices in a sector facing exogenous cost and demand disturbances. We use the model to derive an empirical specification for estimating the cost underlying the joint dynamics of stockouts and prices at a sector level. We then construct empirical responses of sector stockouts and inflation to estimated cost shocks.

This approach provides two additional contributions in this paper. First, we use sector-level price and stockout data to estimate the unobserved cost of replacing unavailable products. This allows us to report the degree to which the pandemic affected the replacement cost. Second, we estimate the impact of cost disturbances over this period on the responses of stockouts and 
inflation. This allows us to re-assess the joint co-movement of stockouts and inflation, while taking into account the endogeneity of stockouts with respect to prices and the underlying costs.

\subsection{Model with Inventories}

The model builds on Kryvtsov and Midrigan (2013). The economy is populated with a unit measure of infinitely-lived ex-ante identical households. Households derive utility from consuming storable products of differentiated varieties $i$ that belong to many sectors, indexed $j$. Households supply hours worked required in the production of consumption goods. There are two types of firms in each sector: intermediate good producers and retailers. In each sector a continuum of competitive intermediate good firms hire labor and produce a homogeneous good using a CobbDouglas technology. ${ }^{10}$ Below we focus on the problem of retailers; full model details are provided in the Appendix.

There is a continuum of monopolistically competitive retailers in sector $j$, each producing a specific variety $i$. Retailers purchase, or "order," goods from intermediate good firms at price $P_{j t}^{I}$, convert them into their specific varieties that they then sell to households or keep in stock. Varieties are subject to i.i.d. demand shocks $v$, drawn from distribution with c.d.f. $F$. The key timing assumption here is that retailer $i$ in sector $j$ places its order $q_{j t}(i)$ and chooses its price $P_{j t}(i)$ prior to realization of idiosyncratic demand shock $v$, but after realization of the sector shocks. This assumption introduces the precautionary motive for holding inventories: firms will choose to carry some stock to the next period to help them meet an unexpected increase in demand.

Retailers face constraints on the price and stock adjustments. Namely, with probability $\xi_{j}$ the price will remain unchanged from the previous period, and with probability $1-\xi_{j}$ the retailer will reset its price. Ordering $q_{j t}(i)$ units entails an additional convex cost expressed as squared deviation of the order size relative to its average $q_{j}, \frac{\phi_{j}}{2}\left(q_{j t+\tau}(i)-q_{j}\right)^{2}$, giving the total dollar cost of the order $P_{j t}^{I}\left(q_{j t}(i)+\frac{\phi_{j}}{2}\left(q_{j t}(i)-q_{j}\right)^{2}\right)$. Convexity of the cost of replacing inventories represents mechanisms that motivate the firm (or its supplier) to smooth orders or production over time. This "production smoothing" motive for holding inventories is standard in inventorycontrol models. ${ }^{11}$

\footnotetext{
${ }^{10}$ It is straightforward to extend this framework to include capital in production technology.

${ }^{11}$ Abel (1985), Ramey and West (1999). Kryvtsov and Midrigan (2010) discuss alternative assumptions of convex
} 
Let $z_{0 j t}(i)$ denote the amount of stock retailer $i$ carries over from period $t-1$. Then the quantity of its product available for sale in period $t$ is

$$
z_{j t}(i)=z_{0 j t}(i)+q_{j t}(i)
$$

Given its price $P_{j t}(i)$, stock available for sale $z_{j t}(i)$, and realization of idiosyncratic shock $v$, the firm's sales in period $t$ are

$$
y_{j t}(i)=\min \left(v\left(\frac{P_{j t}(i)}{P_{j t}}\right)^{-\theta} Y_{j t}, z_{j t}(i)\right),
$$

where $Y_{j t}$ is the total consumption for sector $j$ in period $t$.

Let $Q_{t, t+\tau}$ denote the period- $t$ price of the claim that returns $1 \$$ in period $t+\tau$. The firm's problem is to choose $P_{j t}(i)$ and $z_{j t}(i)$ to maximize

$$
E_{t} \sum_{\tau=0}^{\infty} \xi_{j}^{\tau} Q_{t, t+\tau}\left[P_{j t}(i) y_{j t+\tau}(i)-P_{j t+\tau}^{I}\left(q_{j t+\tau}(i)+\frac{\phi_{j}}{2}\left(q_{j t+\tau}(i)-q_{j}\right)^{2}\right)\right]
$$

subject to demand function (6), measurability restrictions on $P_{j t}(i)$ and $z_{j t}(i)$, constraints on price adjustments, the initial stock of inventories $z_{0 j 0}(i)$, and the law of motion of inventories

$$
z_{0 j t+1}(i)=\left(1-\delta_{j}\right)\left(z_{j t}(i)-y_{j t}(i)\right)
$$

where $\delta_{j}$ is the rate of depreciation of inventories.

The convex cost of adjusting inventories implies that the firm's cost of replacing a unit of inventory stock is increasing in size of the order:

$$
\Omega_{j t}(i)=P_{j t}^{I}\left(1+\phi_{j}\left(q_{j t}(i)-q_{j}\right)\right)
$$

Since the order size depends on the amount of stock carried over from the previous period, the firm that experienced a stockout in period $t-1$ faces higher order costs in period $t$ relative to a similar firm that did not stock out. This feature of the model captures additional costly activities by retailers who face limited product availability, including buying extra inventory, searching for substitutes of out-of-stock products, spending time tracking or replacing suppliers, and re-routing trucks. We rely on this feature of the model in the empirical analysis below.

adjustment cost of inventories and their implications in the context of DSGE business cycle models. 


\subsection{The Empirical Specification for Prices, Stockouts, and Costs}

The empirical specification is derived from the retailer's first-order condition for inventory holdings. Let $v_{j t}(i)=\left(\frac{P_{j t}(i)}{P_{j t}}\right)^{\theta} \frac{z_{j t}(i)}{Y_{j t}}$ denote the value of the demand shock realization for which the retailer sells all available stock without stocking out. Then the likelihood of stockout by retailer $i$ is given by the derivative $\Psi^{\prime}\left(v_{j t}(i)\right)$, where $\Psi\left(v_{j t}(i)\right)=\int \min \left(v, v_{j t}(i)\right) d F(v) .{ }^{12}$

The first-order condition for stock $z_{j t}(i)$ is

$$
\Psi^{\prime}\left(v_{j t}(i)\right)=\frac{\Omega_{j t}(i)-\left(1-\delta_{j}\right) E_{t}\left[Q_{t, t+1} \Omega_{j t+1}(i)\right]}{P_{j t}(i)-\left(1-\delta_{j}\right) E_{t}\left[Q_{t, t+1} \Omega_{j t+1}(i)\right]} .
$$

The left-hand side of (10) is the likelihood of a stockout by retailer $i$. The right-hand side is the function of the firm's price $P_{j t}(i)$, the cost of replacing inventories $\Omega_{j t}(i)$, and the expected discounted cost $\left(1-\delta_{j}\right) E_{t}\left[Q_{t, t+1} \Omega_{j t+1}(i)\right]$. Higher price incentivizes the firm to hold more products in stock, reducing the likelihood of a stockout. In turn, higher expected growth in replacement cost makes the firm shift its stock from period $t+1$ to $t$ to avoid replacing stock in period $t+1$. This too increases stock in period $t$, leading to a lower probability of a stockout.

Condition (10) possesses a property that makes it amenable to empirical analysis. For the firm that sets its price at $P_{j t}(i)$ and faces cost $\Omega_{j t}(i)$, the demand conditions (summarized by $\left.v_{j t}(i)\right)$ enter (10) only via their effect on the probability of a stockout $\Psi^{\prime}\left(v_{j t}(i)\right)$. Because we directly observe stockouts in the data, this means we can analyze condition (10) without knowing demand conditions $v_{j t}(i)$ or shock distribution $F$. We do that in the next section.

To obtain the empirical specification, we normalize all period- $t$ variables by period- $(t-1)$ aggregate price $P_{t-1}$, re-arrange the terms in (10), and integrate them across all firms in sector $j$. This yields the following condition:

$$
p_{j t}\left(O O S_{j t}+C O V_{j t}\right)=\omega_{j t}-\left(1-O O S_{j t}\right)\left(1-\delta_{j}\right) R_{t}^{-1} \pi_{t} E_{t}\left[\omega_{j t+1}\right]
$$

where $O O S_{j t}=\int_{i} \Psi^{\prime}\left(v_{j t}(i)\right) d i$ is the fraction of stockouts in sector $j, p_{j t}=\frac{\int_{i} P_{j t}(i) d i}{P_{t-1}}$ is sector $j$ 's real price, $C O V_{j t}=\operatorname{cov}\left(\Psi^{\prime}\left(v_{j t}(i)\right), \frac{P_{j t}(i)}{P_{j t}}\right)$ is the term that captures the covariance of stockouts and prices across products in sector $j$ in period $t$, and $\omega_{j t}=\frac{\int_{i} \Omega_{j t}(i) d i}{P_{t-1}}$ is the real replacement cost in sector $j$. Finally, we approximate $E_{t}\left[Q_{t, t+1} \omega_{j t+1}\right] \approx R_{t}^{-1} E_{t}\left[\omega_{j t+1}\right]$, where $R_{t}=E_{t}\left[Q_{t, t+1}\right]^{-1}$ is the risk-free rate.

\footnotetext{
${ }^{12}$ Solving the integral yields $\Psi\left(v_{j t}(i)\right)=\int_{0}^{v_{j t}(i)} v d F(v)+v_{j t}(i)\left(1-F\left(v_{j t}(i)\right)\right)$. This implies the derivative $\Psi^{\prime}\left(v_{j t}(i)\right)=1-F\left(v_{j t}(i)\right)$.
} 


\subsection{GMM Estimation}

Although in equation (11) the sector's real replacement cost $\omega_{j t}$ is unobserved, we can use the model to derive its approximation. In the model, a firm experiencing a stockout in period $t-1$ tends to place a higher order in period $t$, and therefore, it faces a higher unit replacement cost, per equation (9). Integrating (9) across firms in sector $j$, and recognizing that higher stockouts in $t-1$ cause higher orders in $t$, yields the following specification for real replacement cost:

$$
\omega_{j t}=a_{j}+b_{j} O O S_{j t-1}+\varepsilon_{j t},
$$

where $\varepsilon_{j t}$ are innovations to period $t$ replacement cost that reflect period $t$ changes in real intermediate good prices $P_{j t}^{I} / P_{t}$ and other costly activities by firms in sector $j$.

Using (12) to substitute $\omega_{j t}$ in empirical specification (11) yields

$$
G\left(p_{j t}, O O S_{j t}, O O S_{j t-1}, C O V_{j t}, R_{t}, \pi_{t} ; a_{j}, b_{j}, \delta_{j}\right)=\varepsilon_{j t},
$$

where $G(\cdot)$ is a non-linear function of observed variables, depreciation rate $\delta_{j}$, and coefficients $a_{j}, b_{j}$; and where $\varepsilon_{j t}$ are innovations in sector $j$ cost from equation (12).

For each sector $j$, we estimate the elasticity $b_{j}$ by a two-step GMM using weekly data for sector price index and the fraction of products out-of-stock. GMM estimation uses the set $\boldsymbol{Z}_{\boldsymbol{t}}$ of $N \geq 1$ instruments. We define the following $N$ orthogonality conditions for GMM estimation:

$$
E\left[Z_{t}^{i} \varepsilon_{j t}\right]=E\left[Z_{t}^{i} G\left(p_{j t}, O O S_{j t}, O O S_{j t-1}, C O V_{j t}, R_{t}, \pi_{t} ; \overline{a_{j}}, b_{j}, \overline{\delta_{j}}\right)\right]=0,
$$

where $Z_{t}^{i}$ is the $i$ th element of the set of instruments $\boldsymbol{Z}_{\boldsymbol{t}}, i=1, \ldots, N$, and $\overline{a_{j}}, \overline{\delta_{j}}$ are calibrated values of $a_{j}, \delta_{j}$. In equations (12)-(13), the errors $\varepsilon_{j t}$ can be conditionally heteroskedastic and serially correlated.

The sample used for estimation starts the week of November 1, 2019, and ends the week of April 30, 2021, spanning 79 weeks. We estimate the empirical model for both out-of-stock measures in the United States: a conservative measure - temporary stockouts (TOOS) - and a broad measure that includes both temporary stockouts and discountinued products (AOOS). GMM estimation uses the following instruments: $\boldsymbol{Z}_{\boldsymbol{t}}=\left[O O S_{j t-1}, O O S_{j t-2}, p_{j t-1}, p_{j t-2}, p_{j t-3}, \boldsymbol{X}_{\boldsymbol{t - 1}}, \boldsymbol{X}_{\boldsymbol{t - 2}}\right]^{\prime}$, where $\boldsymbol{X}_{\boldsymbol{t}}$ is a vector of aggregate (monthly) controls. These controls include 1) the change in the lockdown stringency index from "Oxford-Our World in Data," 13 which scores the number and

\footnotetext{
${ }^{13}$ https://ourworldindata.org/coronavirus-testing.
} 
strictness of government containment and mitigation policies during the COVID-19 pandemic; 2) the change in the number of confirmed infections, from the same source; and 3) the change in operational challenges from the Small Business Pulse Survey collected by the U.S. Census Bureau. ${ }^{14}$ We use a country's 3-month Treasury bill rates as a measure of the risk-free rate $R_{t}$. We compute time series for the cross-section covariance $C O V_{j t}$ between stockouts and relative prices using the micro data - it turns out to be very close to zero and not influential for the results. Finally, in the baseline estimation we assume a weekly depreciation rate of $0.0046 \%$ (2\% monthly rate). We then pick for each sector the value of parameter $a_{j}$ to equal the average real replacement cost implied by (11) over the pre-pandemic period, between November 1, 2019, and January 4, 2020.

\subsection{Estimated Replacement Costs}

Table 4 reports estimation results for two stockout measures in five 1-digit U.S. sectors: "Food and Beverages," "Furnishings and Household," "Health," "Electronics," and "Other Goods" (mostly personal care products).

Estimates indicate a statistically and economically significant effect of stockouts on real replacement cost. The estimated coefficient $b_{j}$ for the effect of out-of-stock on real replacement cost varies from 0.05 for "Food and Beverages" to 0.52 for "Electronics," and all estimates are highly statistically significant. Intuitively, a coefficient value of 0.43 (seen for "Household goods") means that an increase in the weekly temporary stockout rate from $10 \%$ to $20 \%$ increases the replacement cost by roughly $2.2 \%$ in annualized terms. When discontinued products are included in the measure of stockouts, the estimated replacement cost in (12) is more persistent, and not surprisingly, the estimated $b_{j}$ coefficients are somewhat smaller.

The table also provides results of the tests for weak instruments and over-identifying restrictions. The first-stage $F$-statistic for each of the two endogenous regressors in the model, sector price and stockouts, is above the threshold value of 10 in most cases (Stock, Yogo, and Wright, 2002). Hence, the test rejects the null of weak instruments in most cases. The table also reports that $p$-values for Hansen's J-statistic are well above 10\%, implying that the model is correctly

\footnotetext{
${ }^{14}$ The Survey includes questions about supplier delays or delays in product deliveries, and the level of the firm's operating capacity relative to capacity prior to the pandemic, https://portal.census.gov/pulse/data/. We tried different combinations of instruments; including operational challenges but not supply disruptions performs somewhat better than other combinations.
} 
specified. $^{15}$

\begin{tabular}{|c|c|c|c|c|c|c|c|c|}
\hline \multirow{3}{*}{$\begin{array}{l}\text { 1-digit } \\
\text { sectors }\end{array}$} & \multicolumn{4}{|c|}{ Temporary out-of-stock } & \multicolumn{4}{|c|}{ All out-of-stock } \\
\hline & \multirow{2}{*}{$\begin{array}{c}b j \\
\text { (st.dev.) }\end{array}$} & \multicolumn{2}{|c|}{$\begin{array}{l}\text { First-stage } \\
F \text {-statistic }\end{array}$} & \multirow{2}{*}{$\begin{array}{c}\text { Hansen's } \\
J \text {-stat } \\
p \text {-value }\end{array}$} & \multirow{2}{*}{$\begin{array}{c}\text { bj } \\
\text { (st.dev.) }\end{array}$} & \multicolumn{2}{|c|}{$\begin{array}{l}\text { First-stage } \\
F \text {-statistic }\end{array}$} & \multirow{2}{*}{$\begin{array}{c}\text { Hansen's } \\
\text { J-stat } \\
p \text {-value }\end{array}$} \\
\hline & & price & OOS & & & price & OOS & \\
\hline Food \& Bev & $\begin{array}{c}0.05^{* * *} \\
(0.00)\end{array}$ & 15.56 & 237.52 & 0.68 & $\begin{array}{c}0.04^{* * *} * \\
(0.00)\end{array}$ & 13.10 & 13.31 & 0.61 \\
\hline Household & $\begin{array}{c}0.43^{* * *} \\
(0.02)\end{array}$ & 60.12 & 163.94 & 0.82 & $\begin{array}{c}0.18^{* * *} \\
(0.02)\end{array}$ & 50.62 & 7.15 & 0.57 \\
\hline Health & $\begin{array}{c}0.09^{* * * *} \\
(0.00)\end{array}$ & 10.97 & 96.43 & 0.86 & $\begin{array}{c}0.05^{* * *} * \\
(0.00)\end{array}$ & 11.93 & 16.50 & 0.73 \\
\hline Electronics & $\begin{array}{c}0.52^{* * * *} \\
(0.02)\end{array}$ & 34.04 & 11.05 & 0.82 & $\begin{array}{c}0.17^{* * *} * \\
(0.00)\end{array}$ & 27.34 & 12.97 & 0.78 \\
\hline Other Goods & $\begin{array}{c}0.02^{* * * *} \\
(0.01)\end{array}$ & 6.53 & 38.92 & 0.65 & $\begin{array}{c}0.04^{* * *} \\
(0.00)\end{array}$ & 7.24 & 7.59 & 0.97 \\
\hline
\end{tabular}

Table 4: Estimation Results for the United States

Notes: The table reports coefficients $b_{j}$ in specification for sector $j$ replacement cost (12) estimated by two-step GMM estimator and a weight matrix that allows for heteroskedasticity and autocorrelation up to four lags with the Bartlett kernel. The table also provides the first-stage $F$-statistic for testing weak instruments for two endogenous regressors (price and OOS), and $p$-values for Hansen's $J$-statistic to test over-identifying restrictions in the GMM. ${ }^{*} \mathrm{p}<0.10,{ }^{* *} \mathrm{p}<0.05,{ }^{* * *} \mathrm{p}<0.01$.

These differences in the estimated sensitivity of cost to stockouts across sectors can be related to different dynamics of prices and stockouts. According to the first-order condition for inventories (10), if the firm faces higher cost but does not adjust its price, its stockout probability is higher. But if the firm can increase its price, the demand for the firm's product decreases and the likelihood of a stockout is dampened. Hence, conditional on the cost, stockouts and prices are negatively correlated. Therefore, when the increase in stockouts is accompanied by a rise in prices, the estimated increase in replacement cost is higher than if prices are flat or falling.

Table 5 provides changes in stockouts, prices, and estimated costs between January 2020 and April 2021 across consumption sectors in the United States. ${ }^{16}$ The last two columns highlight the importance of distinguishing the two types of stockouts for our estimates of the replacement costs. In particular, prices for "Food and Beverages" products increased by $0.8 \%$, but because temporary stockouts eventually fell to below pre-pandemic levels, the estimated costs of replacing inventories are $0.41 \%$ lower. By contrast, the incidence of discontinued products is persistently

\footnotetext{
${ }^{15}$ When we conduct estimation using 34 3-digit U.S. sectors, the first-stage $F$-statistic rejects weak instruments for the endogenous price regressor in 27 sectors and in 31 sectors for the temporary out-of-stock regressor. When the broad stockout measure is used, the weak instruments are rejected in 27 sectors (price) and 22 sectors (all out-of-stock). In all cases, the $p$-values for Hansen's over-identifying restrictions test are well above 0.10 .

${ }^{16}$ See Appendix Figure A5 for details on the changes over time in each sector.
} 
high in this sector, and therefore, the corresponding cost estimate is $1.33 \%$ above the prepandemic level.

\begin{tabular}{|c|c|c|c|c|c|}
\hline \multirow{3}{*}{$\begin{array}{l}\text { 1-digit } \\
\text { sectors }\end{array}$} & \multicolumn{3}{|c|}{ Data } & \multicolumn{2}{|c|}{ Estimated Cost } \\
\hline & $\begin{array}{c}\text { Price Index } \\
\%\end{array}$ & $\begin{array}{c}\text { TOOS } \\
\text { ppt }\end{array}$ & $\begin{array}{l}\text { AOOS } \\
\text { ppt }\end{array}$ & $\begin{array}{c}\text { TOOS } \\
\%\end{array}$ & $\begin{array}{c}\text { AOOS } \\
\%\end{array}$ \\
\hline & (1) & $(2)$ & (3) & (4) & $(5)$ \\
\hline Food \& Bev & 0.80 & -14.15 & 23.27 & -0.41 & 1.33 \\
\hline Household & 0.71 & 1.16 & 5.09 & 0.73 & 2.01 \\
\hline Health & -1.14 & -2.18 & -0.02 & -1.17 & -0.77 \\
\hline Electronics & -1.12 & 3.83 & 33.69 & 1.99 & 4.19 \\
\hline Other Goods & -2.38 & -0.11 & 4.60 & -0.54 & -0.71 \\
\hline
\end{tabular}

Table 5: Cumulative Changes in Stockouts, Prices, and Estimated Replacement Costs between January 2020 and April 2021, United States

Notes: The table reports \% change of the sector price index between the week of January 4, 2020, and the week of April 30, 2021 (column 1), ppt difference between average fraction of products out-of-stock in April 2021 and in January 2020 (columns 2 and 3), and \% difference between average estimated nominal replacement cost in April 2021 and in January 2020 (columns 4 and 5). Estimation uses two out-of-stock measures: temporary stockouts (TOOS) and all stockouts (AOOS). Wald-test $p$-values for the hypothesis that the estimated cost differences in columns 4 and 5 are equal to zero are all below 0.001 .

In other sectors, the sign of the estimated cost change is the same for two stockout measures, but the magnitude increases when we account for permanent stockouts. For example, "Furnishings and Household" products prices increased by $0.71 \%$, with both stockout measures remaining above the pre-pandemic levels by May 2021, implying estimated costs that are between $0.73 \%$ to $2.01 \%$ higher. In "Electronics," prices fell but stockouts increased the most, both on a temporary and permanent basis, implying estimated replacement costs that are 1.99\% to $4.19 \%$ higher than before the pandemic. In the "Health" sector, prices fell by $1.14 \%$ and both stockout measures are either at or below the pre-pandemic levels. Accordingly, the estimated cost of replacing inventories declined by $1.17 \%$ and $0.77 \%$, depending on the type of stockouts. Finally, the estimated costs are also lower for "Other Goods", representing mostly personal care products (watches, jewelry, appliances for personal care), because prices fell by $2.38 \%$ but stockouts remained either at or slightly above pre-pandemic levels.

In all sectors, the estimated cost is lower than at its peak in Spring 2020, suggesting that replacement costs have been gradually falling since the beginning of the pandemic. 


\subsection{Inflation Responses to Cost Shocks}

In Section 3.2, we estimated stockout and inflation responses to stockout disturbances, treating those disturbances as exogenous. The model in this section provides a mechanism according to which stockouts and prices respond endogenously to exogenous variation in real replacement cost. We already estimated the replacement cost process using observed variations in sector prices and stockouts. Therefore, we can now estimate dynamic responses of stockouts and inflation at a sector level to that sector's cost disturbance $\varepsilon_{j t}$ from cost equation (12). For estimation we use exactly the same method as in Section 3.2. Figure 8 provides estimated responses.
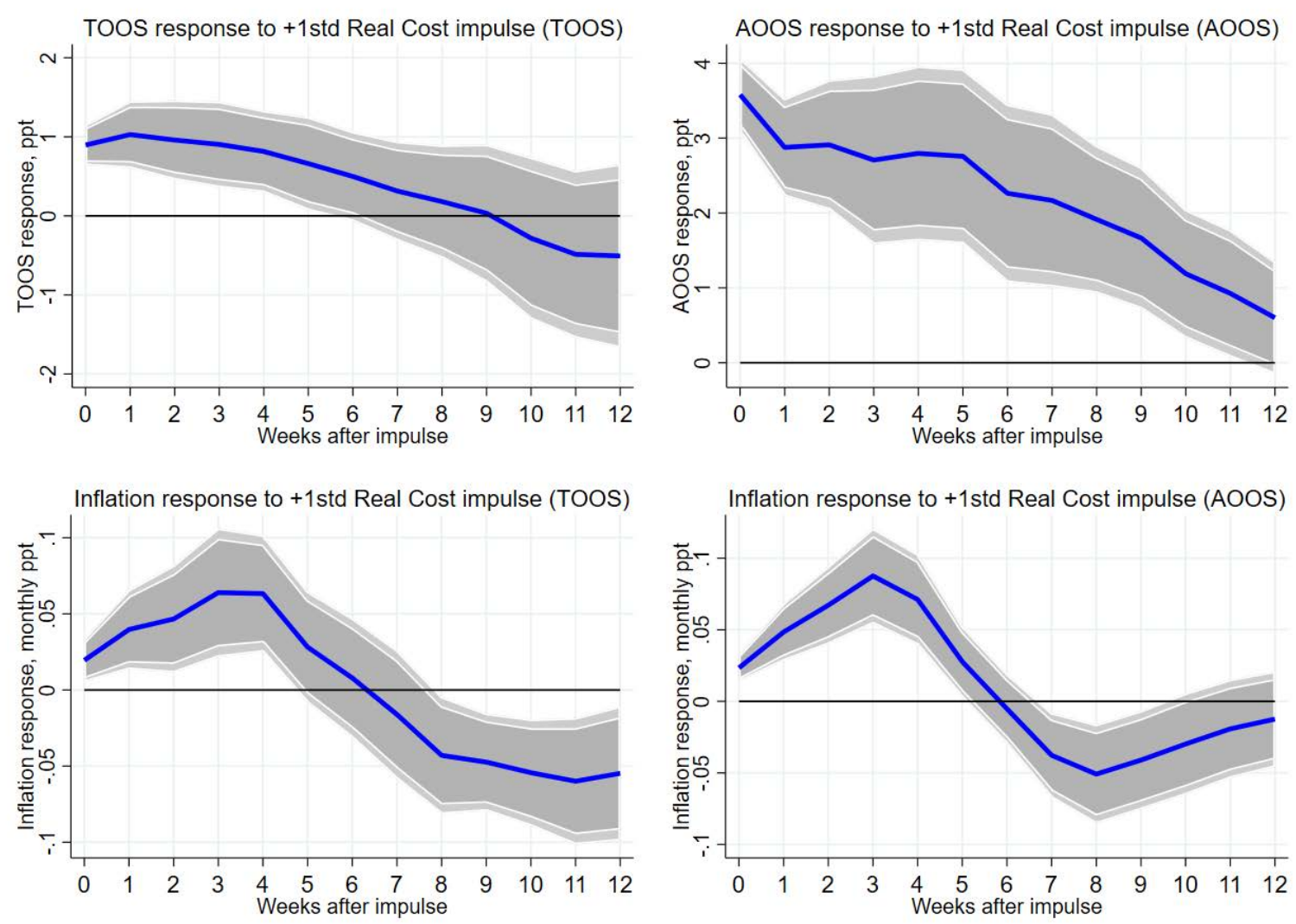

Figure 8: Responses to Real Replacement Cost Shocks in 3-Digit U.S. Sectors

Notes: The figure provides responses to a +1 standard deviation real replacement cost impulse (in \%) estimated using specification (4) for 3-digit sectors in the U.S. Estimation uses two out-of-stock measures: temporary stockouts (TOOS) and all stockouts (AOOS). Shocks: real replacement cost based on temporary stockouts (left plots) and real replacement cost based all stockouts (right plots). Responding variables: temporary stockout rates (top left plot); all stockout rates (top right plot); inflation (bottom plots). Shaded areas outline $90 \%$ and $95 \%$ bands based on Driscoll-Kraay standard errors.

There are several additional takeaways from these responses. First, there is a clear dynamic effect of cost shocks on stockouts and prices at a sector level. In response to a +1 -standard- 
deviation increase in real replacement cost, temporary stockouts increase by 0.9 ppt on impact and decrease back to zero within two months. Likewise, in response to cost derived from all stockouts, the response of all stockouts is +3.6 ppt on impact, decreasing back to pre-shock levels within 3 to 4 months. For both shock measures, inflation increases for the first 6 weeks reaching $0.06 \mathrm{ppt}$ and $0.09 \mathrm{ppt}$ (monthly rate) within the first month, and then decreases by about the same magnitude for the next 6 weeks or so. This implies that an impulse to real cost permanently increases the price level and has an inflationary impact lasting about 3 to 4 months.

Second, a cost shock increases both stockouts and prices contemporaneously. This feature is consistent with the mechanism in the model in Section 4.1 where firms respond to a cost hike by raising their prices or by cutting their stocks and tolerating higher stockouts. Like in the estimation where stockouts were treated as exogenous, prices respond slower than stockouts, perhaps reflecting constraints in price adjustment. During the first month after the shock, prices gradually rise, helping firms dampen the initial rise in stockouts.

These additional results underscore the importance of accounting for endogeneity of stockouts when estimating the inflationary effects of cost disturbances. When stockouts are treated as exogenous, the negative effect of rising prices on stockouts is ignored, and the short-run response of inflation is underestimated relative to the response in stockouts. Secondly, the dynamic link between stockouts and future cost (see equation 12) is also ignored, which means that inflation responses will appear to be more persistent. Indeed, compared to responses in Figure 7, inflation responses in Figure 8 are stronger immediately after the cost shock, but are also less persistent.

\subsection{Other Countries}

The key features of stockout and inflation responses are robust to estimation using 3-digit sector data in 7 countries: United States, Canada, China, France, Germany, Japan, and Spain (see Appendix). One notable difference is that in the United States stockouts are more responsive to

cost shocks, and inflation is less responsive, both by roughly a half. That is, in response to cost jumps, U.S. retailers are more willing to tolerate higher stockouts rather than higher prices. 


\section{Conclusion}

Rising inflation in 2020 amid the COVID-19 pandemic spurred a lively debate on whether the years of low inflation were ending. Supply disruptions and cost pressures are often mentioned by policy-makers and economists as playing a role, but little is known empirically about their actual impact on prices. Rich variation of prices and shortages during the pandemic provide fertile ground for analyzing their mutual relationship.

In this paper, we construct a high-frequency measure of product shortages by using data collected directly from the websites of large retailers in multiple sectors and countries. We focus not just on the "out-of-stock" signals that are visible to consumers, but also on the higher incidence of discontinued goods, which are harder to detect. Our stockout measures show that shortages were widespread early on in the pandemic, affecting far more than just toilet paper or disinfecting wipes. Over time, the composition of shortages evolved from many temporary stockouts to mostly discontinued products, concentrated in fewer sectors. This may have made the stockout problem less visible, but not less important.

We find that an unexpected jump in a retail sector's stockout rate is associated with an inflationary effect that peaks within a couple of months. Whether measured directly from stockouts or through our model-based estimation of the underlying replacement costs, the impact on prices is significant. For the United States, for example, an increase in a stockout rate from $10 \%$ to $20 \%$ raises monthly inflation by about 0.10 ppt. The inflationary effect of such standalone shock lasts on average 3 to 4 months.

We draw several conclusions from this analysis. Product shortages likely reflect emergent cost pressures, due, for example, to supply bottlenecks. Unexpected shortages are quickly followed by inflation. During a protracted event, such as a global health pandemic, shortages are temporary at first but gradually become more permanent in nature and increasingly concentrated in only some sectors. Persistently high inflation rates in these sectors can be explained by a series of adverse cost shocks, due for example, to recurring waves of virus infections. As cost pressures dissipate, inflation outlook will increasingly depend on other factors, such as the effect of the fiscal stimulus, the adjustment of inflation expectations, and diffusion of cost pressures via domestic and international production networks. 


\section{References}

Abel, A. B. (1985): "Inventories, Stock-Outs and Production Smoothing," The Review of Economic Studies, 52(2), 283-293.

Aguirregabiria, V. (1999): "The Dynamics of Markups and Inventories in Retailing Firms," Review of Economic Studies, 66(2), 275-308, Publisher: Oxford University Press.

Bernstein, J., and E. Tedeschi (2021): "Pandemic Prices: Assessing Inflation in the Months and Years Ahead," Discussion paper, Council of Economic Advisers.

BILs, M. (2016): "Deducing Markups from Stockout Behavior," Research in Economics, 70(2), $320-331$.

BiLs, M., And J. A. Kahn (2000): "What Inventory Behavior Tells Us about Business Cycles," American Economic Review, 90(3), 458-481.

Cavallo, A. (2013): "Online and Official Price Indexes: Measuring Argentina's Inflation," Journal of Monetary Economics, pp. 152-165.

_ (2017): "Are Online and Offine Prices Similar? Evidence from Large Multi-Channel Retailers," American Economic Review, 107(1).

Cavallo, A., E. Cavallo, and R. Rigobon (2014): "Prices and Supply Disruptions during Natural Disasters," Review of Income and Wealth, 60.

Cavallo, A., and R. Rigobon (2016): "The Billion Prices Project: Using Online Data for Measurement and Research," Journal of Economic Perspectives, 30(2), 151-78.

Driscoll, J., And A. KraAy (1998): "Consistent Covariance Matrix Estimation With Spatially Dependent Panel Data," The Review of Economics and Statistics, 80(4), 549-560, Publisher: MIT Press.

Fitch, A. (2021): "Chip Shortages Are Starting to Hit Consumers. Higher Prices Are Likely," Wall Street Journal.

Foster, K., B. Meyer, and B. Prescott (2021): "Inflation Expectations Reflect Concerns over Supply Disruptions, Crimped Capacity," Policy Hub. 
Hassan, T. A., S. Hollander, L. Van Lent, M. Schwedeler, and A. Tahoun (2020): "Firm-Level Exposure to Epidemic Diseases: Covid-19, SARS, and H1N1," Discussion paper, National Bureau of Economic Research.

Helper, S., and E. Soltas (2021): "Why the Pandemic Has Disrupted Supply Chains," Discussion paper, Council of Economic Advisers.

JoRDÀ, O. (2005): "Estimation and Inference of Impulse Responses by Local Projections," American Economic Review, 95(1), 161-182.

Kang, J. (2021): "Why You Can't Find Everything You Want at Grocery Stores," Wall Street Journal.

Krolikowski, P., and K. Naggert (2021): "Semiconductor Shortages and Vehicle Production and Prices," Economic Commentary, 2021-17.

Kryvtsov, O., and V. Midrigan (2010): "Inventories and Real Rigidities in New Keynesian Business Cycle Models," Journal of the Japanese and International Economies, 24(2), 259-281.

- (2013): "Inventories, Markups, and Real Rigidities in Menu Cost Models," Review of Economic Studies, 80(1), 249-276.

Mahajan, K., and S. Tomar (2021): "COVID-19 and Supply Chain Disruption: Evidence from Food Markets in India," American Journal of Agricultural Economics, 103(1), 35-52.

Meier, M., And E. Pinto (2020): "Covid-19 Supply Chain Disruptions," Covid Economics, 48, 139-170.

Ramey, V. A., and K. D. West (1999): "Chapter 13 Inventories," vol. 1 of Handbook of Macroeconomics, pp. 863-923. Elsevier.

Stock, J., M. Yogo, and J. Wright (2002): "A Survey of Weak Instruments and Weak Identification in Generalized Method of Moments," Journal of Business and Economic Statistics, $20,518-529$.

UN (2018): "UN Classification of Individual Consumption According to Purpose (COICOP)," UN Statistics Division.

U.S. Census Bureau (2021): "Small Business Pulse Survey," Discussion paper. 


\section{A Additional Tables and Figures}

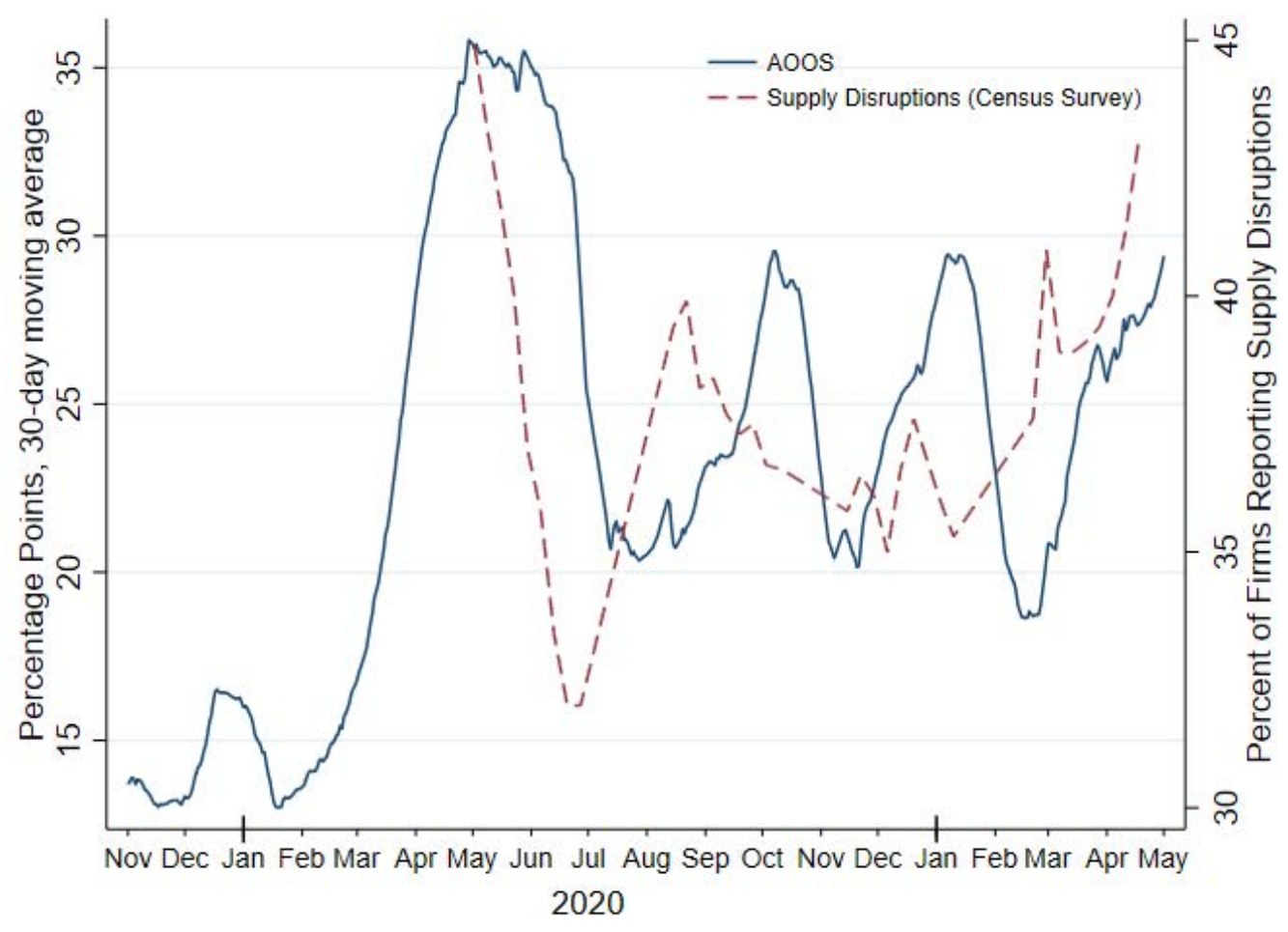

Figure A1: Stockouts (AOOS) vs. U.S. Census Survey of Small Business Disruptions

Notes: This graph compares our measure of all stockouts in the United States with the percentage of firms that reported experiencing supply disruption in the "Small Business Pulse Survey" conducted by the U.S. Census Bureau between May 2010 and April 2021. See https://portal.census.gov/pulse/data/\#about. 


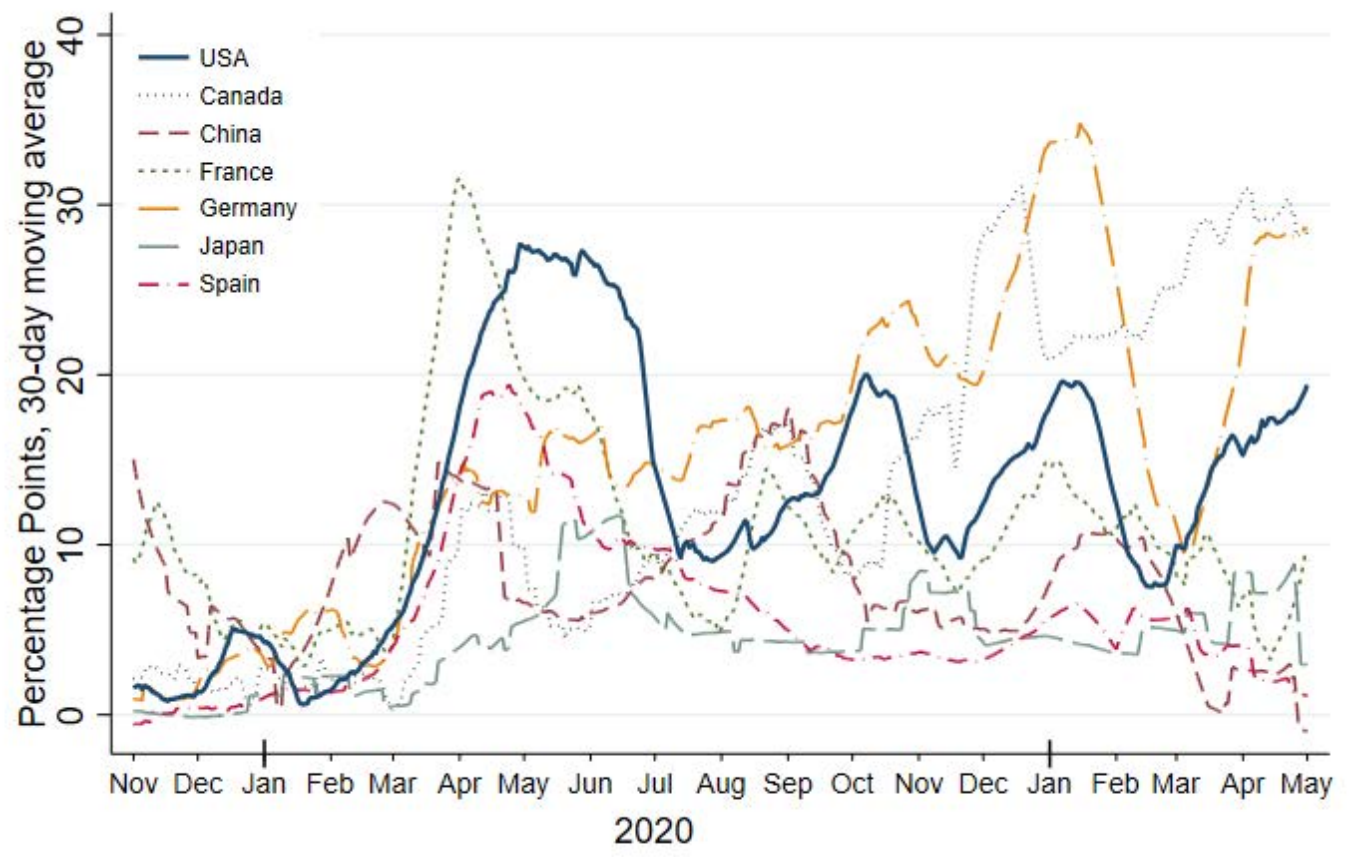

Figure A2: All Stockouts in 7 Countries

Notes: The initial level of AOOS varies greatly by country, so in order to facilitate the comparison, here we plot the change relative to pre-pandemic levels, given by $A O O S_{t, c}-A O O S_{J a n 2020, c}$. 


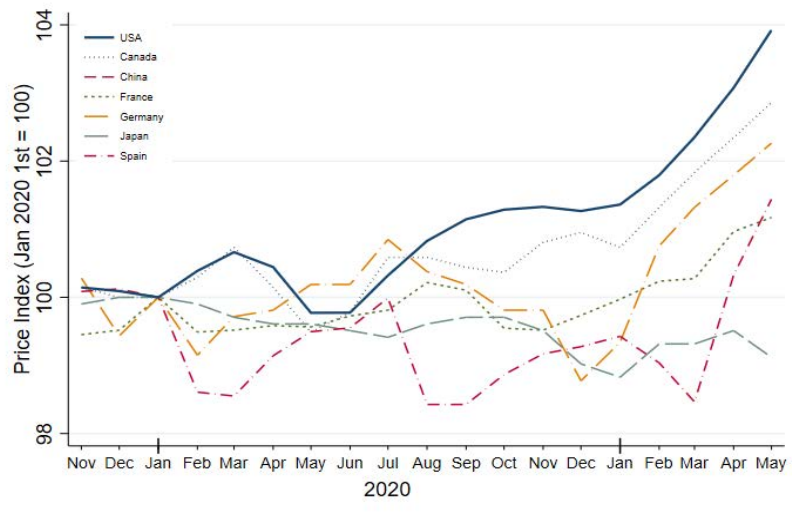

(a) CPI - Price Index

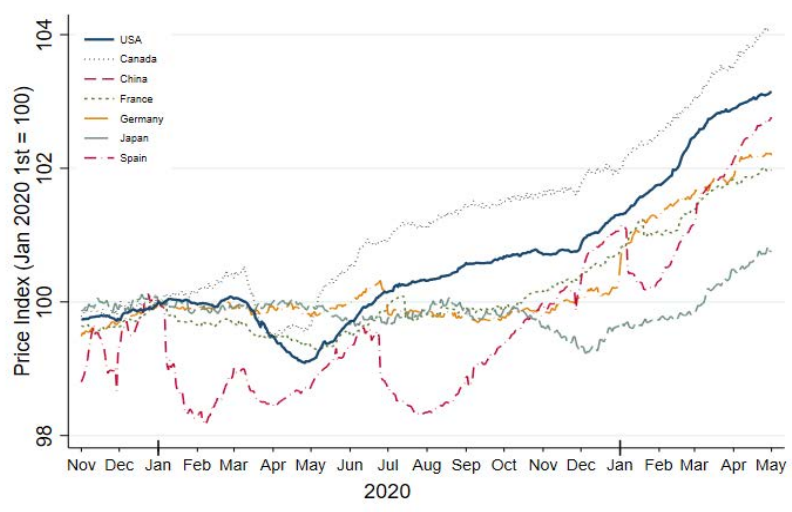

(c) Online - Price Index

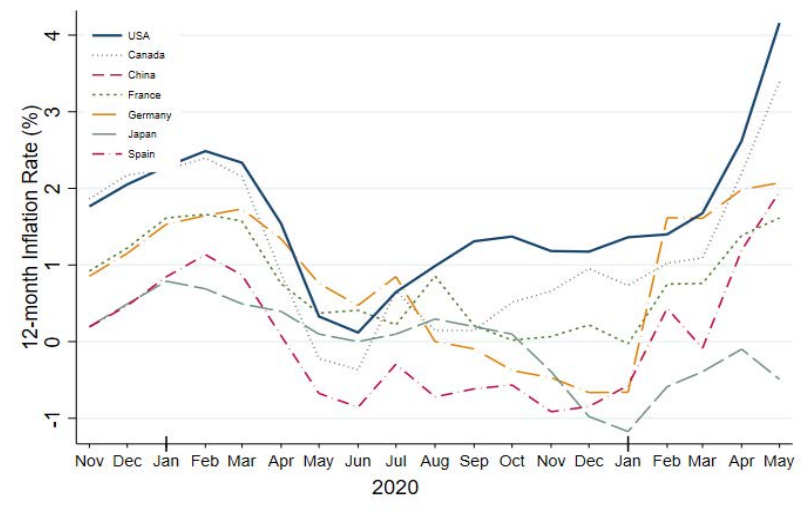

(b) CPI - Annual Inflation

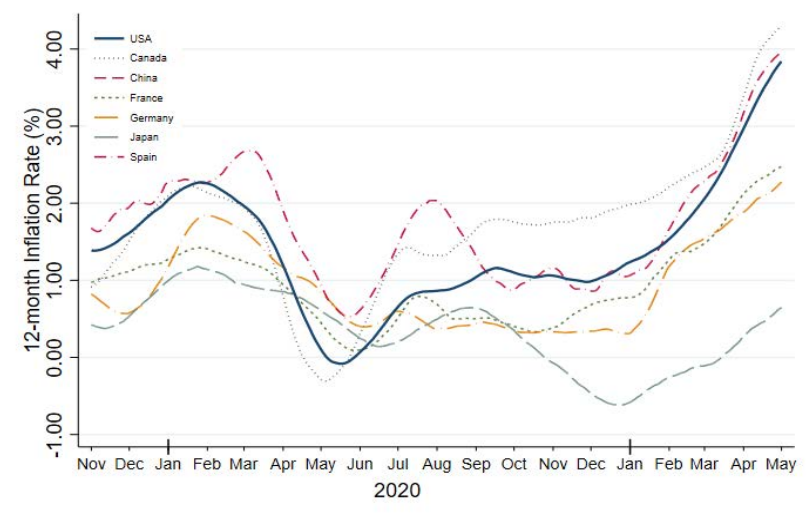

(d) Online - Annual Inflation

\section{Figure A3: Inflation Rates}

Notes: The top graphs show the price index and the annual inflation rate for the official all-items CPI in each country. The bottom graphs show equivalent indices constructed by PriceStats using the same online-data source used in our paper. 


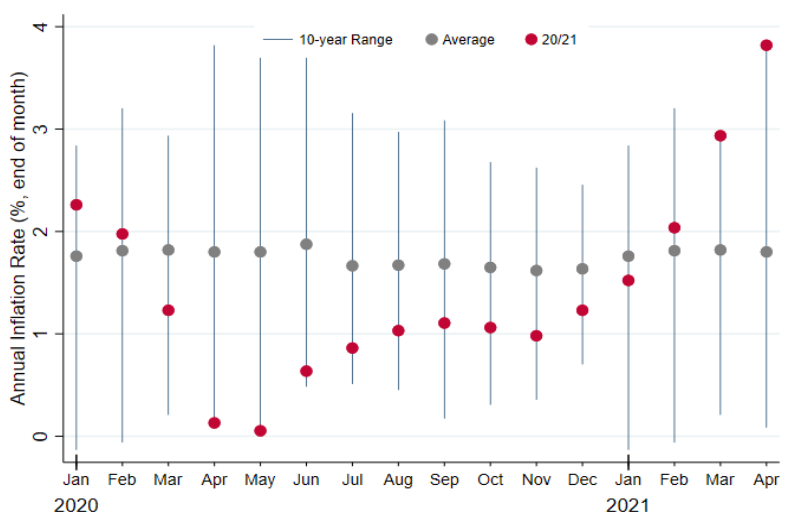

(a) All Items

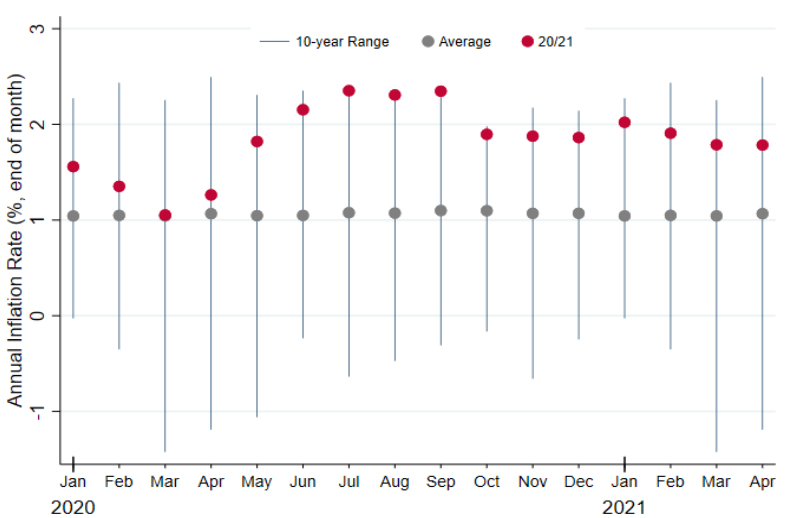

(b) Electronics

Figure A4: U.S. Online Inflation in 2020-21 versus 10-year Averages

Notes: In these plots we compare the annual inflation rate in online prices during the pandemic to the average and range of values in the past 10 years. We use price indices computed by PriceStats, both at the aggregate "All Items" level (right) and for "Electronics" (right). The plot on the left shows that the annual inflation rate in March and April 2021 has been at the highest level recorded for those months in the past 10 years. The plot on the right shows that the annual inflation for electronics has been roughly 1 ppt above normal levels since June 2020. 


\begin{tabular}{lccccc} 
Monthly inflation & \multicolumn{1}{l}{} & & \\
OOS (\%) & 0.008 & -0.004 & -0.004 & -0.007 & -0.014 \\
& $(0.001)$ & $(0.000)$ & $(0.001)$ & $(0.001)$ & $(0.001)$ \\
Obs. & 5,357 & 5,204 & 3,896 & 974 & 1,461 \\
\hline Annual inflation & & & & & \\
OOS (\%) & 0.004 & 0.023 & 0.007 & -0.031 & -0.109 \\
& $(0.001)$ & $(0.001)$ & $(0.001)$ & $(0.005)$ & $(0.004)$ \\
Obs. & 5,346 & 5,192 & 3,888 & 972 & 1,458 \\
\hline \hline
\end{tabular}

Table A1: Impact of Stockouts on Inflation Rates in the United States - with Time FEs

Notes: This table shows the coefficient of a regression at the 3-digit category level in the United States. The dependent variable is either the monthly (top panel) or annual (bottom panel) inflation rate, in \%. The independent variable is the level of stockouts (both temporary and permanent), in \%. All regressions are run using daily data and include 3-digit category dummies and time fixed effects. Robust standard errors are shown in parentheses.

\begin{tabular}{lccccccc}
\hline \hline & USA & Canada & China & Germany & Spain & France & Japan \\
\hline \multirow{2}{*}{ Annual inflation } & & & & & & & \\
OOS (\%) & 0.031 & 0.026 & 0.015 & 0.012 & -0.009 & -0.011 & -0.045 \\
& $(0.001)$ & $(0.003)$ & $(0.002)$ & $(0.002)$ & $(0.001)$ & $(0.003)$ & $(0.003)$ \\
Obs. & 16,856 & 17,120 & 14,094 & 15,552 & 16,302 & 17,010 & 16,454 \\
\hline \hline
\end{tabular}

\section{Table A2: Impact of Stockouts on Inflation Rates by Country - with Time FEs}

Notes: This table shows the coefficient of a regression at the 3-digit category level in the United States. The dependent variable is the annual inflation rate. The independent variable is the level of stockouts (both temporary and permanent). All regressions are run using daily data and include 3-digit category dummies and period fixed effects. Robust standard errors are shown in parentheses. 
Food and Beverages, USA
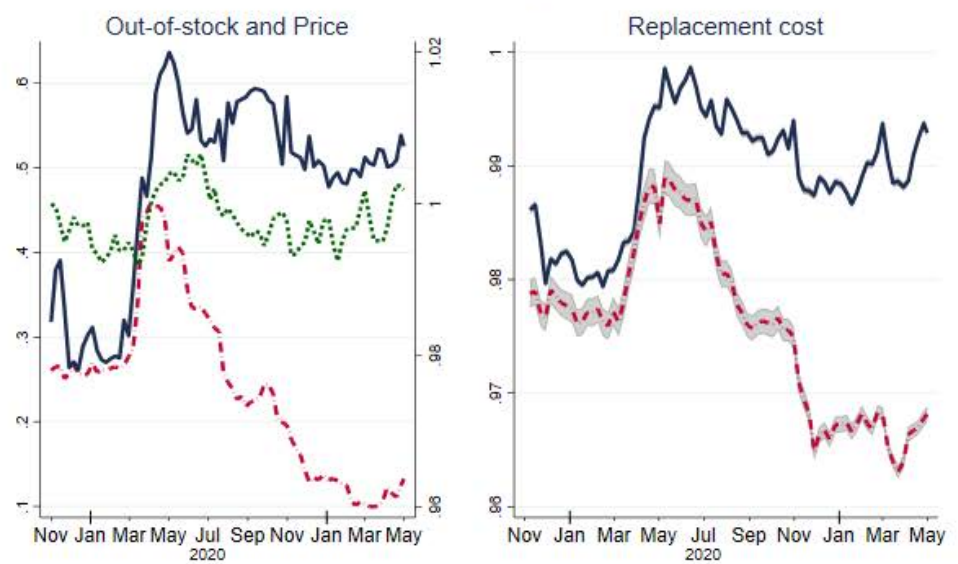

Health, USA
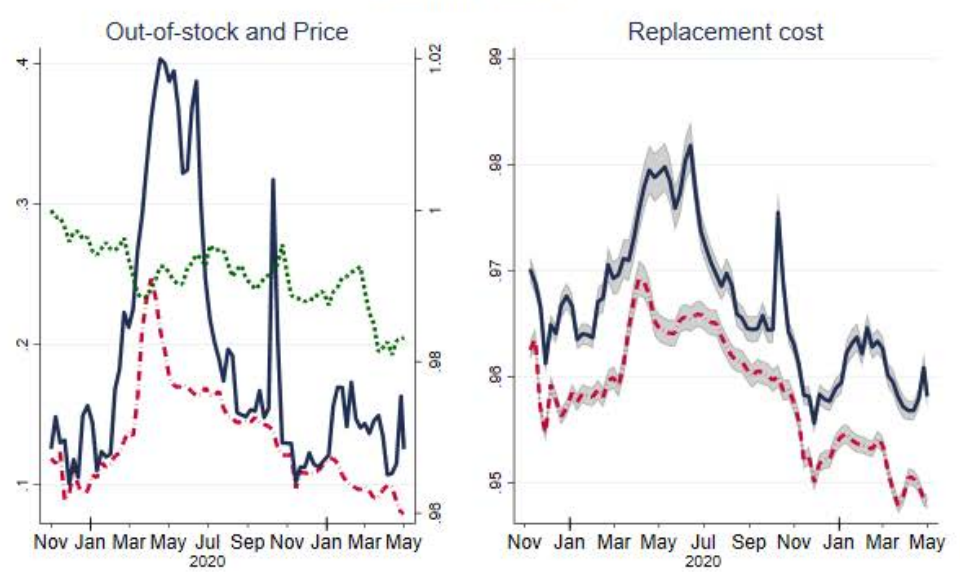

Furnishings \& Household, USA
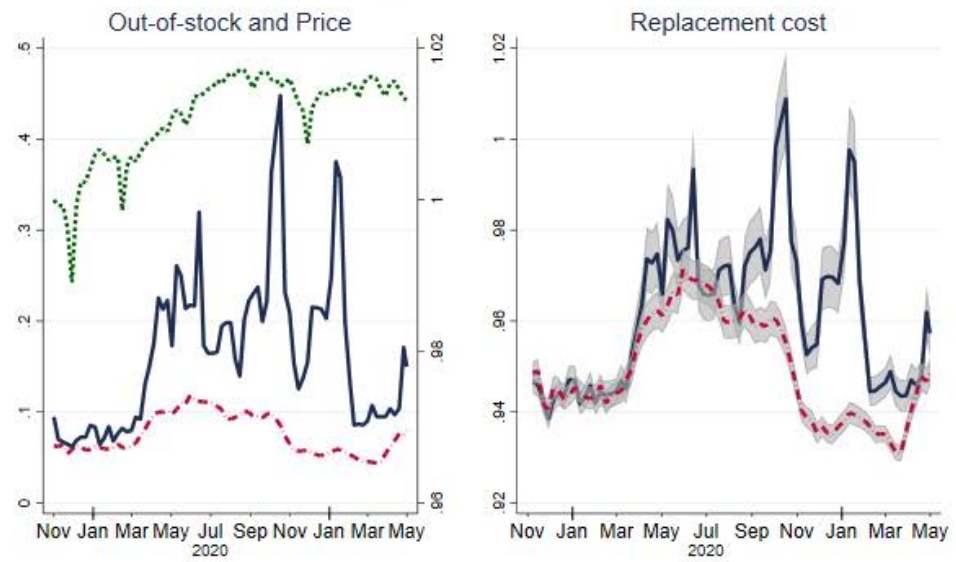

Electronics, USA
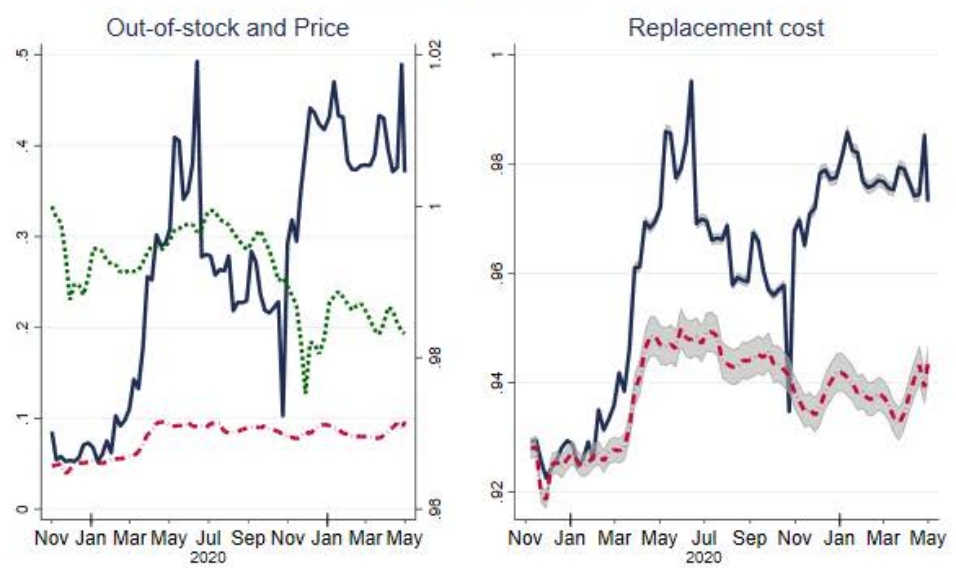

AOOS

\section{TOOS}

m = " = " = - Price (right axis)

Figure A5: Stockouts, Prices, and Estimated Costs in 1-Digit U.S. Sectors

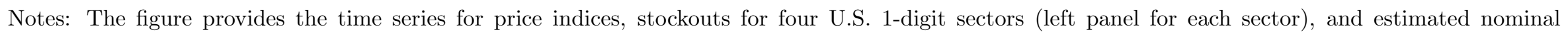

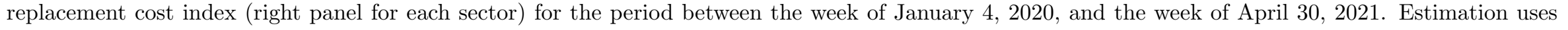

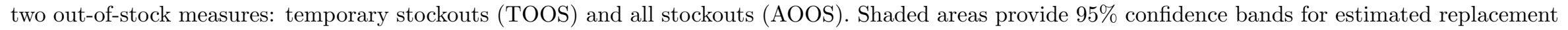
cost. 

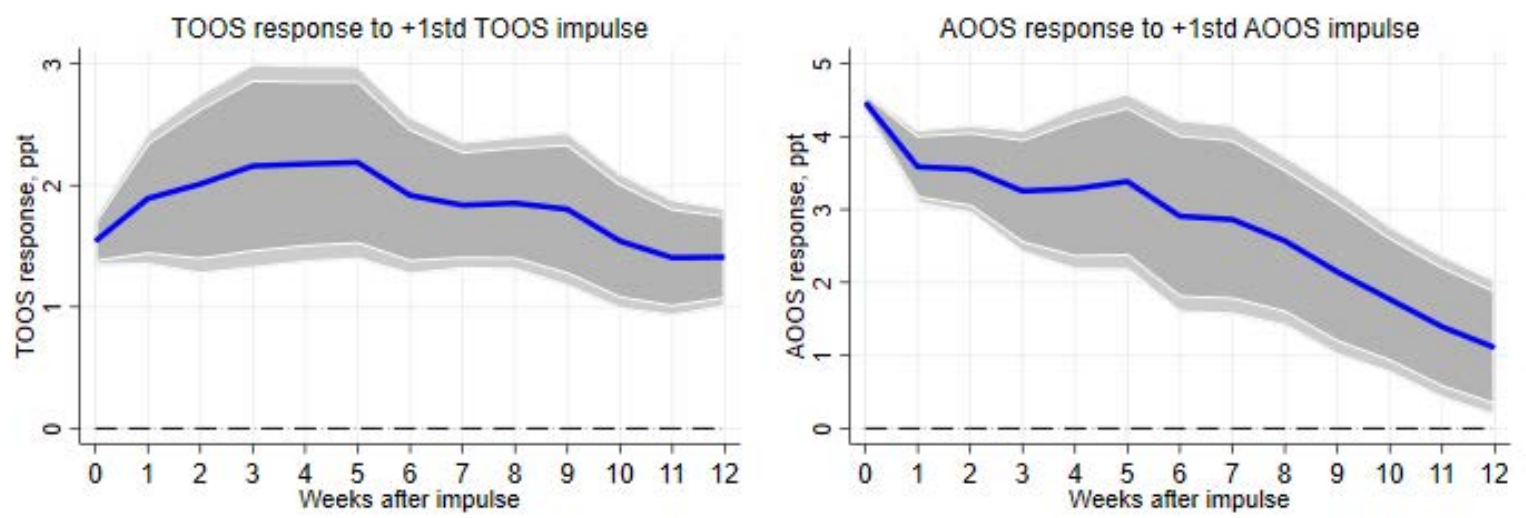

Figure A6: Stockout Persistance in 3-Digit U.S. sectors

Notes: This figure complements Figure 7 in the text, where we show the inflation responses to the same shock. The figure provides stockout responses to a +1 standard deviation stockout impulse estimated using specification (4) for 3-digit sectors in the U.S. Shocks: temporary stockouts (left plot) and all stockouts (right plot). Shaded areas outline $90 \%$ and $95 \%$ bands based on Driscoll-Kraay standard errors.
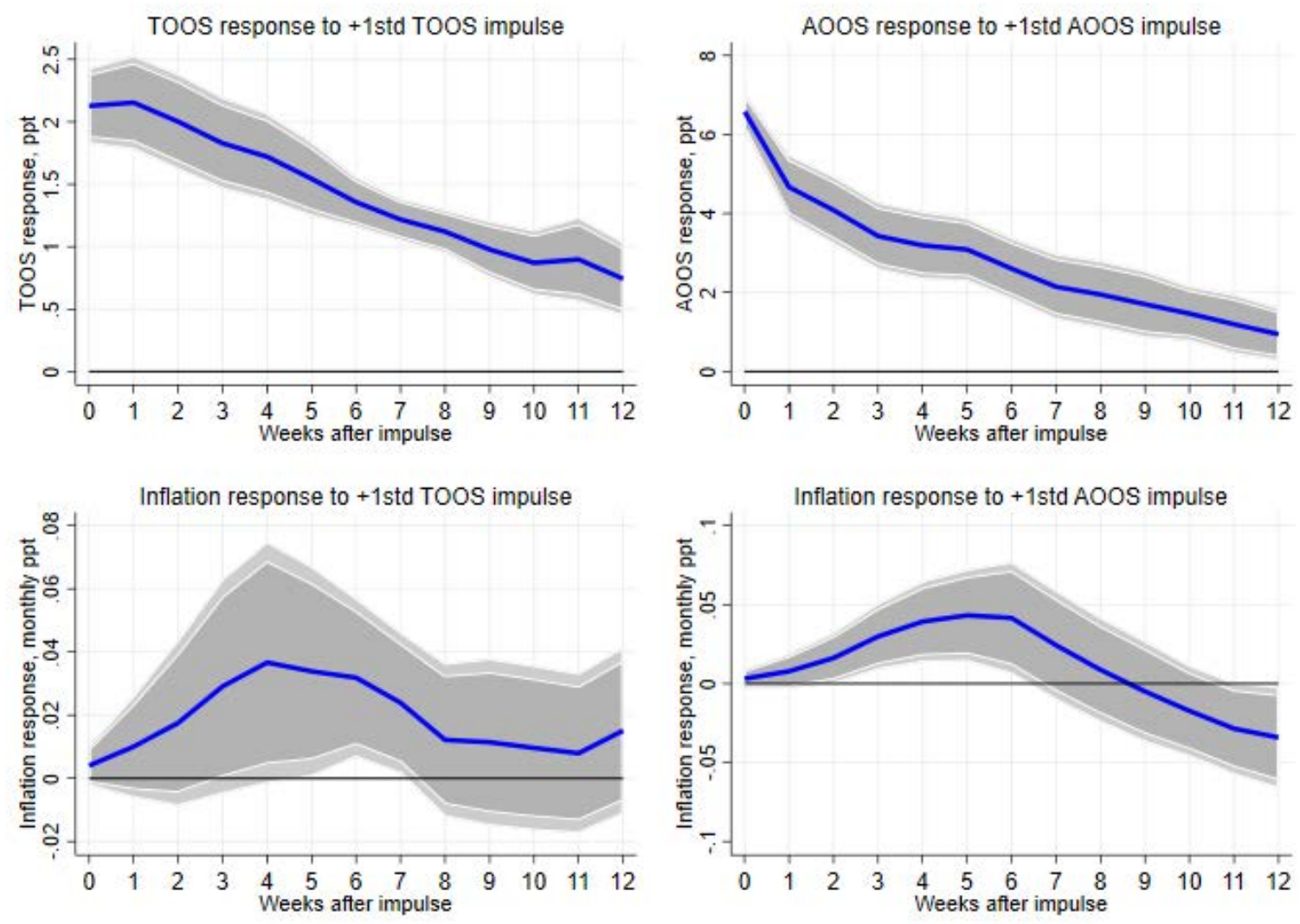

Figure A7: Responses to Stockout Shocks in 3-Digit Sectors in 7 Countries

Notes: The figure provides responses to a +1 standard deviation stockout impulse estimated using specification (4) for 3-digit sectors in the U.S., Canada, China, France, Germany, Japan, and Spain. Estimation uses two out-of-stock measures: temporary stockouts (TOOS) and all stockouts (AOOS). Shocks: temporary stockouts (left plots) and all stockouts (right plots). Responding variables: temporary stockout rates (top left plot); all stockout rates (top right plot); inflation (bottom plots). Shaded areas outline $90 \%$ and $95 \%$ bands based on Driscoll-Kraay standard errors. 

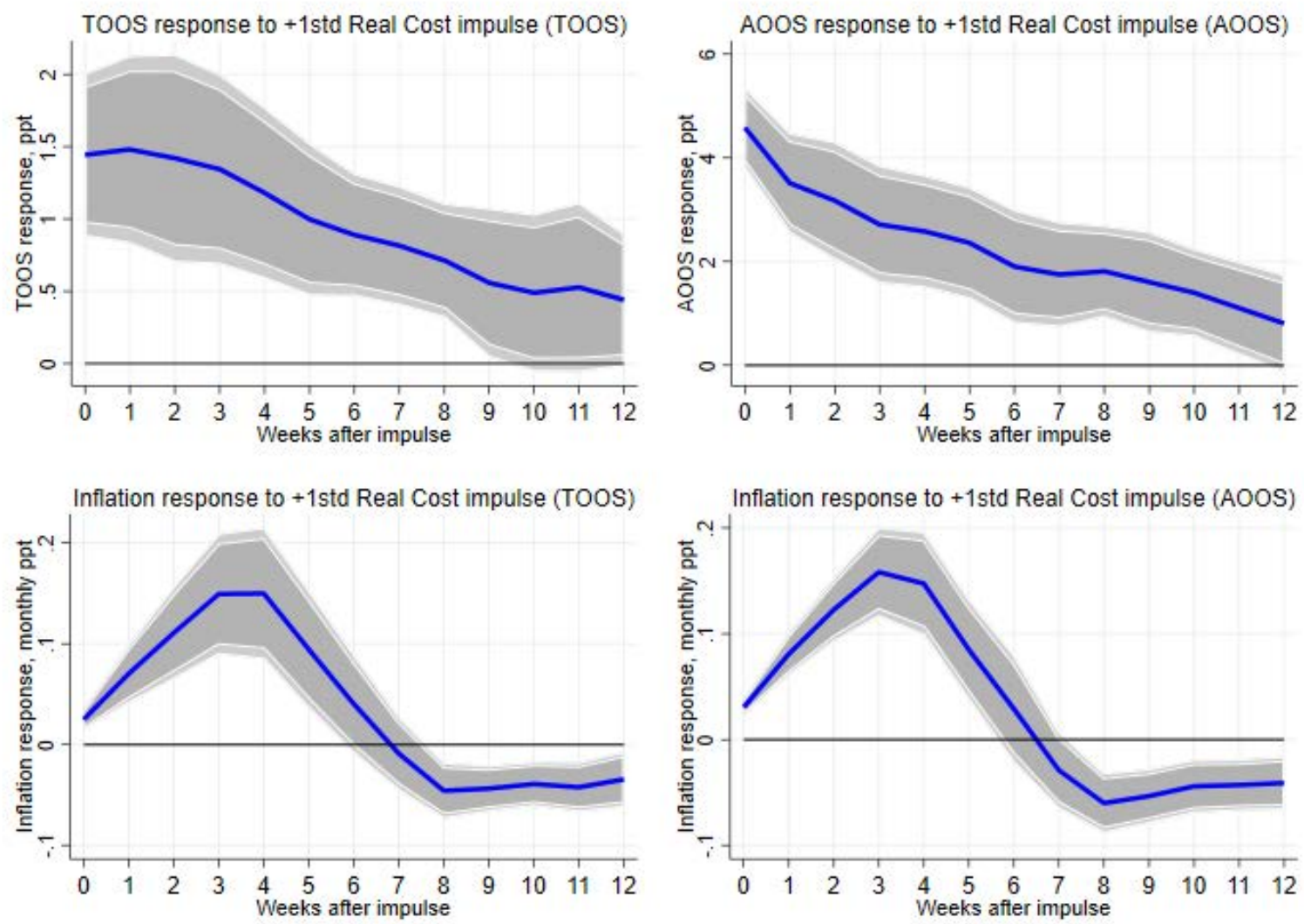

Figure A8: Responses to Real Replacement Cost Shocks in 3-Digit Sectors in 7 Countries

Notes: The figure provides responses to $a+1$ standard deviation real replacement cost impulse estimated using specification (4) for 3-digit sectors in the U.S., Canada, China, France, Germany, Japan, and Spain. Estimation uses two out-of-stock measures: temporary stockouts (TOOS) and all stockouts (AOOS). Since measures of supply disruptions or operational capacity are only available for the United States, we exclude them from the set of instruments. Also we assume $C O V_{j t}$ to be zero for countries other than the United States. Shocks: real replacement cost based on temporary stockouts (left plots) and real replacement cost based on all stockouts (right plots). Responding variables: temporary stockout rates (top left plot); all stockout rates (top right plot); inflation (bottom plots). Shaded areas outline $90 \%$ and $95 \%$ bands based on Driscoll-Kraay standard errors. 


\section{B A Model of Stockouts and Prices}

What can the joint behavior of sector prices and stockouts tell us about the underlying cost pressures facing retailers? In this section, we present a model of a sector of monopolistically competitive firms that face costs of adjusting their prices and their inventory holdings. The model builds on Kryvtsov and Midrigan's 2013 model where firms hold inventories to buffer against possible stockouts. The optimal stock of inventories - and the associated probability of a stockout - is determined by the trade-off between the firm's cost of replenishing the stock and its price level. At a sector level, this implies a dynamic relationship between sector price, the fraction of stockouts, and the cost of replenishing inventories. We use weekly time series for sector price and stockouts to estimate unobserved sector replacement cost. The estimation uses the identifying assumption derived in the model: a firm that experiences a stockout faces a higher cost of replenishing an additional unit of stock in the next period.

\section{B.1 Setup}

The economy is populated with a unit measure of infinitely-lived ex-ante identical households. Households derive utility from consuming storable products of differentiated varieties $i$ that belong to many sectors, indexed $j$. Households supply hours worked required in the production of consumption goods.

There are two types of firms in each sector: intermediate good producers and retailers. In each sector a continuum of competitive intermediate good firms invest in capital stock, hire labor, and produce a homogeneous good using a Cobb-Douglas technology. The homogeneous good is sold to monopolistically competitive retail firms in that sector for producing consumption varieties. Below we present problems of household's final consumption and intermediate good producers. Retailer's problem and derivation of the first-order condition for inventories are provided in the main text.

\section{B.2 Final Consumption}

The final consumption good for sector $j$ is obtained by combining product varieties sold by retailers in sector $j$ :

$$
Y_{j t}=\left[\int_{0}^{1} v_{j t}^{1 / \theta}(i) y_{j t}^{d}(i)^{\frac{\theta-1}{\theta}} d i\right]^{\frac{\theta}{\theta-1}}
$$


where $y_{j t}^{d}(i)$ is the quantity of variety $i$ in sector $j, \theta$ is the elasticity of substitution across varieties, and $v_{j t}(i)$ is the demand shock specific to variety $i$. We assume that $v_{j t}(i)$ is an i.i.d. log-normal variable. Kryvtsov and Midrigan (2013) discuss the implications and robustness of this assumption.

At the beginning of period $t$, retailers hold $z_{j t}(i)$ units of variety in stock and available for sale at price $P_{j t}(i)$. Occasionally, retailers will not be able to satisfy the demand for their product and will sell all of their stock, i.e., stock out. We assume that, in case of a stockout, all households get an equal share of the variety $i$ of sector $j$ final good.

Household chooses $Y_{j t}$ and $\left\{y_{j t}^{d}(i)\right\}$ to maximize

$$
P_{j t} Y_{j t}-\int_{0}^{1} P_{j t}(i) y_{j t}^{d}(i) d i
$$

subject to the stockout constraint

$$
y_{j t}^{d}(i) \leqslant z_{j t}(i) \forall i
$$

and the final good production technology (B.1). Cost minimization implies the following demand for variety $i$ :

$$
y_{j t}^{d}(i)=v_{j t}(i)\left(\frac{P_{j t}(i)+\mu_{j t}(i)}{P_{j t}}\right)^{-\theta} Y_{j t},
$$

where $\mu_{j t}(i)$ is the multiplier on the constraint (B.2), and $P_{j t}$ is the price of final good in sector j

$$
P_{j t}=\left[\int_{0}^{1} v_{j t}(i)\left[P_{j t}(i)+\mu_{j t}(i)\right]^{1-\theta} d i\right]^{\frac{1}{1-\theta}} .
$$

Because some retailers stock out, in equilibrium $P_{j t}$ is larger than $\hat{P}_{j t}=\left[\int_{0}^{1} v_{j t}(i) P_{j t}(i)^{1-\theta} d i\right]^{\frac{1}{1-\theta}}$, the usual formula for the aggregate price index. Thus financing the same level of the final consumption good requires a higher expenditure in this setup with love-for-variety and stockouts.

Note also that if the stockout constraint binds, then $\mu_{j t}(i)$ satisfies

$$
P_{j t}(i)+\mu_{j t}(i)=\left(\frac{z_{j t}(i)}{v_{j t}(i) P_{j t}^{\theta} Y_{j t}}\right)^{1 / \theta}
$$

The left-hand side is the desired price that a retailer with stock $z_{j t}(i)$ would like to set to avoid a binding stockout constraint. Since such a retailer cannot sell more than the available stock, it would like to raise its price. Hence, price adjustment frictions give rise to stockouts because they prevent retailers from raising their prices. 


\section{B.3 Intermediate Input Producers}

A continuum of competitive intermediate good firms in sector $j$ acquire labor service of type $j$ $N_{j t}$ and produce homogeneous good $M_{j t}$ using a Cobb-Douglas technology ${ }^{17}$

$$
M_{j t}=N_{j t} .
$$

The homogeneous good is sold at the competitive price $P_{j t}^{I}$ to retailers as input in the production of product varieties. The intermediate good producer chooses sequences of output $M_{j t}$ and labor services $N_{j t}$ to maximize

$$
E_{0} \sum_{t=0}^{\infty} Q_{0, t}\left[P_{j t}^{I} M_{j t}-W_{j t} N_{j t}\right]
$$

subject to the technology constraint (B.3), and where $Q_{0, t}$ is the period-0 price of the claim that returns $1 \$$ in period $t .^{18}$ The firm takes wages as given.

Cost minimization gives the expression for marginal cost of intermediate good production, which in turn is equal to the price of the intermediate input due to perfect competition:

$$
P_{j t}^{I}=W_{j t} .
$$

\footnotetext{
${ }^{17}$ It is straightforward to extend this framework to include capital in production technology.

${ }^{18}$ From the household's problem we have that $Q_{0, t}=\pi\left(s^{t} \mid s^{0}\right) \frac{U^{\prime}\left(C_{t}\right)}{P_{t}}$, where $U^{\prime}\left(C_{t}\right)$ is marginal utility of consumption, $P_{t}$ is the price of $C_{t}$, and $\pi\left(s^{t} \mid s^{0}\right)$ is the probability measure of the state history $s^{t}$. See Appendix for details.
} 